\title{
Preparation and Enhanced Properties of $\mathrm{Fe}_{3} \mathrm{O}_{4}$ Nanoparticles Reinforced Polyimide Nanocomposites
}

Daowei Ding, ${ }^{1}$ Xingru Yan,${ }^{1,2}$ Xi Zhang,,${ }^{1,2}$ Qingliang He, ${ }^{1}$ Bin Qiu,,${ }^{1}$ Dawei Jiang, ${ }^{1}$ Huige Wei, ${ }^{1,2}$ Jiang Guo, ${ }^{1}$ Ahmad Umar, ${ }^{3 *}$ Luyin Sun, ${ }^{4}$ Qiang Wang, ${ }^{5}$ Mojammel A Khan, ${ }^{6}$ David P. Young, ${ }^{6}$ Thomas C. Ho, ${ }^{1}$ Zhanhu Guo ${ }^{1, *}$ and Suying Wei ${ }^{1,2, *}$

${ }^{1}$ Integrated Composites Laboratory (ICL), Dan F Smith Department of Chemical Engineering, Lamar University, Beaumont, TX 77710 USA;

E-mail: zhanhu.guo@lamar.edu

${ }^{2}$ Department of Chemistry and Biochemistry, Lamar University, Beaumont, TX 77710 USA; Email: suying.wei@lamar.edu

${ }^{3}$ Department of Chemistry, Faculty of Science and Arts and Promising Centre for Sensors and Electronic Devices, Najran University, P.O. Box: 1988, Najran 11001, Kingdom of Saudi Arabia E-mail: ahmadumar786@gmail.com

\footnotetext{
${ }^{4}$ Department of Chemical \& Biomolecular Engineering and Polymer Program, Institute of Materials Science, University of Connecticut, Storrs, CT 06269 USA

${ }^{5}$ College of Environmental Science and Engineering, Beijing Forestry University, 35 Qinghua East Road, Haidian District, Beijing 100083, China ${ }^{6}$ Department of Physics and Astronomy, Louisiana State University, Baton Rouge, LA 70803, USA
} 


\begin{abstract}
Polyimide (PI) nanocomposite reinforced with $\mathrm{Fe}_{3} \mathrm{O}_{4}$ nanoparticles (NPs) at various NPs loadings levels of 5.0, 10.0, 15.0, and $20.0 \mathrm{wt} \%$ were prepared. The chemical interactions of the $\mathrm{Fe}_{3} \mathrm{O}_{4}$ NPs/PI nanocomposites were characterized using Fourier Transform Infrared (FT-IR) spectroscopy. X-ray Diffraction (XRD) results revealed that the addition of NPs had a significant effect on the crystallization of PI. Scanning electron microscope (SEM) and the atomic force microscope (AFM) were used to characterize the dispersion and surface morphology of the $\mathrm{Fe}_{3} \mathrm{O}_{4}$ NPs and the PI nanocomposites. The obtained optical band gap of the nanocomposites characterized using Ultraviolet-Visible Diffuse Reflectance Spectroscopy (UV-Vis DRS) was decreased with increasing the $\mathrm{Fe}_{3} \mathrm{O}_{4}$ loading. Differential scanning calorimetry (DSC) results showed a continuous increase of $\mathrm{T}_{\mathrm{g}}$ with increasing the $\mathrm{Fe}_{3} \mathrm{O}_{4}$ NPs loading. Some differences were observed in the onset decomposition temperature between the pure PI and nanocomposites since the NPs and the PI matrix were physically entangled together to form the nanocomposites. The contact angle of pure PI was larger than that of $\mathrm{Fe}_{3} \mathrm{O}_{4} / \mathrm{PI}$ nanocomposites films, and increased with increasing the loading of $\mathrm{Fe}_{3} \mathrm{O}_{4}$. The degree of swelling was increased with increasing the $\mathrm{Fe}_{3} \mathrm{O}_{4}$ loading and the swelling time. The dielectric properties of the nanocomposite were strongly related to the $\mathrm{Fe}_{3} \mathrm{O}_{4}$ loading levels. The $\mathrm{Fe}_{3} \mathrm{O}_{4} / \mathrm{PI}$ magnetic property also had been improved with increasing the loading of the magnetic nanoparticles.
\end{abstract}

Keywords: Polyimide; $\mathrm{Fe}_{3} \mathrm{O}_{4}$; magnetic properties; mechanical properties; optical properties; dielectric properties 


\section{Introduction}

Polymer nanocomposites (PNCs) or inorganic-organic hybrid materials have attracted both academic and industrial attentions during the last few decades due to their extraordinary properties because of the property synergism among the components, and the potential wide applications.[1-6] These materials have gained great interests due to the remarkable improvement in properties such as mechanical,[7] magnetic,[8] optical,[9-11] thermal and electrical, $[12,13]$ compared to pure polymers or conventional micron- and macro- composites. Traditionally, polymer matrix was filled with natural or synthetic inorganic compounds in order to improve their properties. Typically the nanofillers can be divided based on their basic physical structures as particles, fibers or plates. Polyimide (PI), a class of thermal stable polymers, is well known and widely used in different fields of industries for their extremely high thermal and chemical stability and excellent electrical and mechanical properties.[14-16] For example, cobalt-containing PI has been studied and applied for moisture sensing and absorption.[17] The well-dispersed hexagonal boron nitride (h-BN) composite films with oriented cross-linked liquid crystalline (LC) polyimide were obtained as high thermally conductive materials.[18] The PI has been used to fabricate pervaporation membranes for the separation of ethanol/water mixtures.[19] The well-dispersed single-walled and multiple-walled carbon nanotubes functionalized with polyimide derivatives were obtained.[20] Soluble polyimide containing benzimidazole rings synthesized via one-pot synthetic method have been studied for inter-level dielectrics.[21] The control of the composite layer microstructure was achieved by embedding nickel NPs in the 
polyimide matrix to catalyze the hydrogenation and decomposition.[22] A wide variety of other NPS such as polyhedral oligomeric silsesquioxane (POSS),[23] silica,[24] copper,[25] and $\mathrm{TiO}_{2}[26]$ has also been introduced to the PI matrix to obtain various unique properties.

During the past decades, magnetic nanoparticles have attracted long-standing interest owing to their unique properties and potential applications. In particular, $\mathrm{Fe}_{3} \mathrm{O}_{4} \mathrm{NPs}$, an important member of spinel type ferrite, have extensive applications not only in the field of magnetic recording but also in the areas of ferrofluid, [27, 28] magnetoresistance sensing, ${ }^{[29]}$ drug delivery,[30, 31] bifunctional materials,[32, 33] mineral separation, [34, 35] and efficient heat transfer applications.[36] The $\mathrm{Fe}_{3} \mathrm{O}_{4} \mathrm{NPs}$ have also been applied to form diversified core/shell nanoparticles with other materials such as FePt,[37] $\mathrm{Au},[38] \mathrm{Ag}[39]$ and FeO.[40] All of these applications are attributed to their extraordinary physical and chemical properties, including high specific surface area, low toxicity, superparamagnetic activities, and simple separation by an external magnet. However, the method of incorporating $\mathrm{Fe}_{3} \mathrm{O}_{4}$ NPs to fabricate PI nanocomposites with magnetic properties is rarely reported so far.

In this work, the $\mathrm{Fe}_{3} \mathrm{O}_{4} \mathrm{NPs} / \mathrm{PI}$ nanocomposites with various $\mathrm{Fe}_{3} \mathrm{O}_{4}$ nanoparticle loadings (5, 10, 15, and $20 \mathrm{wt} \%$ ) were fabricated. The chemical structures of the $\mathrm{Fe}_{3} \mathrm{O}_{4}$ NPs/PI nanocomposites were characterized. Scanning electron microscope (SEM) and atomic force microscope (AFM) were used to characterize the dispersion and the surface morphology of the $\mathrm{Fe}_{3} \mathrm{O}_{4} \mathrm{NPs}$, and $\mathrm{Fe}_{3} \mathrm{O}_{4}$ NPs/PI nanocomposites. The optical properties were characterized by ultraviolet-visible diffuse reflectance spectroscopy (UV-Vis DRS). The magnetic properties of 
the nanocomposites were investigated and a Physical Properties Measurement System (PPMS) by Quantum Design. The effects of $\mathrm{Fe}_{3} \mathrm{O}_{4}$ NPs on the crystallization of PI were studied by X-ray diffraction (XRD). The thermal stability of the nanocomposites compared with pure PI was assessed by differential scanning calorimetry (DSC) and thermo gravimetric analysis (TGA). The dielectric properties and mechanical properties of the nanocomposite films were characterized by LCR meter and tensile test, respectively. The contact angles and degree of swelling of the nanocomposite films were also tested.

\section{Experimental section}

\subsection{Materials}

Polyimide (PI, powder, Matrimid 5218 US) was provided by Huntsman Advanced Materials Americas, Inc. Scheme 1 shows the molecular structure of PI. N,N-Dimethylformamide (DMF, 99.9\%, anhydrous) was purchased from Fisher Scientific Inc. The $\mathrm{Fe}_{3} \mathrm{O}_{4}$ NPs with an average size of $20 \mathrm{~nm}$ were obtained from Nanjing Emperor Nano Material Co., Ltd., China. The $\mathrm{Fe}_{3} \mathrm{O}_{4}$ nanoparticles were dried at $140{ }^{\circ} \mathrm{C}$ to remove residual water.<smiles>Cc1ccc(C2(C)CC(C)(C)c3ccc(N4C(=O)c5ccc(C(=O)c6ccc7c(c6)C(=O)N(C)C7=O)cc5C4=O)cc32)cc1</smiles>

Scheme 1: Molecular structure of polyimide (Matrimid 5218 US) 


\subsection{Preparation of Polyimide and Nanocomposite Solutions}

The PI/DMF polymer solutions with a PI loading of 8.0, 10.0, 15.0 and $20.0 \mathrm{wt} \%$ were prepared by mechanical stirring $(200 \mathrm{rpm})$ overnight at room temperature to completely dissolve the

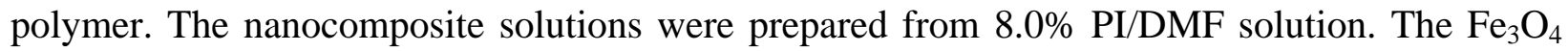
NPs $(5.0,10.0,15.0$, and $20.0 \mathrm{wt} \%$, with regard to the weight of PI) were added into the polymer solution, respectively. After completely wetting the $\mathrm{Fe}_{3} \mathrm{O}_{4} \mathrm{NPs}$ with the polymer solution, both mechanical stirring (300 rpm) and ultra-sonication were simultaneously applied for 30 minutes to fully disperse the NPs in PI/DMF solution. Pure PI and $\mathrm{Fe}_{3} \mathrm{O}_{4}$ NPs/PI nanocomposite solutions were both used for casting films. All the experiments were performed at room temperature.

\subsection{Fabrication of Pristine PI and Nanocomposites Films}

Pure PI and $\mathrm{Fe}_{3} \mathrm{O}_{4}$ NPs/PI nanocomposite films were prepared by casting viscous polymer solutions on a horizontal glass mold. Then the films were dried at $80{ }^{\circ} \mathrm{C}$ in a vacuum oven for 12 $\mathrm{h}$ to remove solvent. Finally the films were dried at $140{ }^{\circ} \mathrm{C}$ under vacuum for $48 \mathrm{~h}$ to remove the residual solvent and stored for further characterization.

\subsection{Characterization}

Fourier transform infrared spectroscopy (FT-IR) characterization of pure PI and its nanocomposite films was performed on a FT-IR spectrometer coupled with an ATR accessory (Bruker Inc. Vector 22) in the range from 500 to $4000 \mathrm{~cm}^{-1}$ at a resolution of $4 \mathrm{~cm}^{-1}$. X-ray diffraction (XRD) analysis was conducted on a Bruker AXS D8 Discover diffractometer with 
General Area Detector Diffraction System (GADDS) operating with a $\mathrm{Cu}-\mathrm{K} \alpha$ radiation source filtered with a graphite monochromator $(\lambda=1.5406 \AA$ ). The data were collected at scanning rate of $4^{\circ} \mathrm{min}^{-1}$ in a range of 5 to $80^{\circ}$. The morphology of pure $\mathrm{PI}$ and $\mathrm{Fe}_{3} \mathrm{O}_{4} / \mathrm{PI}$ nanocomposite films was characterized by scanning electron microscopy (SEM, Hitachi S-3400) and atomic force microscopy (AFM, Agilent 5600 system with multipurpose $90 \mathrm{~mm}$ scanner). The mechanical properties of pure PI and its $\mathrm{Fe}_{3} \mathrm{O}_{4}$ nanocomposite films were characterized by tensile test. The glass transition temperature $\left(\mathrm{T}_{\mathrm{g}}\right)$ was measured with differential scanning calorimetry (DSC, TA Instruments). The $\mathrm{T}_{\mathrm{g}}$ of the samples was determined as the midpoint temperature of the transition region in the second heating cycle. The DSC heat flow and temperature were calibrated with an indium standard. The thermal stability was investigated with a thermo gravimetric analysis (TGA Q-500, TA Instruments). The TGA was conducted on pure PI and its $\mathrm{Fe}_{3} \mathrm{O}_{4}$ nanocomposite films in the temperature range of $30-900{ }^{\circ} \mathrm{C}$ with a heating rate of $10{ }^{\circ} \mathrm{C} / \mathrm{min}$ and a nitrogen flow rate of $60 \mathrm{~mL} / \mathrm{min}$. The magnetic properties tests were carried out at room temperature in a 9 T Physical Properties Measurement System (PPMS) by Quantum Design. The dielectric properties were investigated by a LCR meter (Agilent, E4980A) equipped with a dielectric test fixture (Agilent, 16451B) at the frequency ranging from 20 to $2 \times 10^{6} \mathrm{~Hz}$ at room temperature. The contact angles were measured by the sessile drop method with a contact angle analyzer (Contact angle analyzer, Future Digital Scientific Corp.). Pure PI and its $\mathrm{Fe}_{3} \mathrm{O}_{4}$ nanocomposite films were immersed in n-Hexadecane at $50^{\circ} \mathrm{C}$ for the swelling test. The degree of swelling of films was measured after 4, 8, 12, 16, 20, 24, 48, and 72 hours. 


\section{Results and Discussion}

\subsection{Microstructure of the $\mathrm{Fe}_{3} \mathrm{O}_{4} / \mathrm{PI}$ Nanocomposites Films (SEM/AFM)}
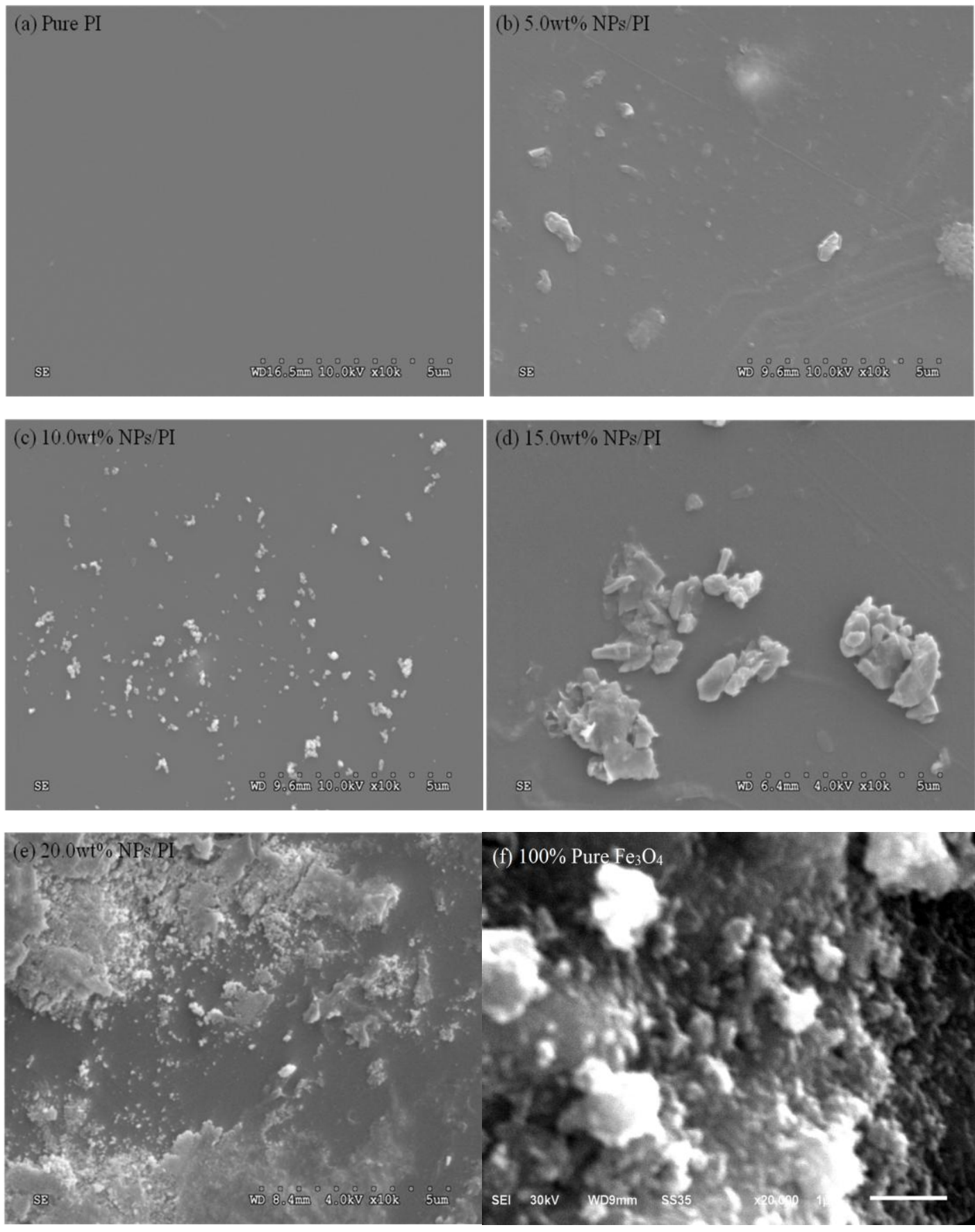

Fig. $1 \mathrm{SEM}$ images of pure PI and $\mathrm{Fe}_{3} \mathrm{O}_{4} / \mathrm{PI}$ nanocomposites films with a $\mathrm{Fe}_{3} \mathrm{O}_{4}$ nanoparticle loading of (a) 0.0, (b) 5.0, (c) 10.0, (d) 15.0, (e) 20.0 and (f) $100.0 \mathrm{wt} \%$. 

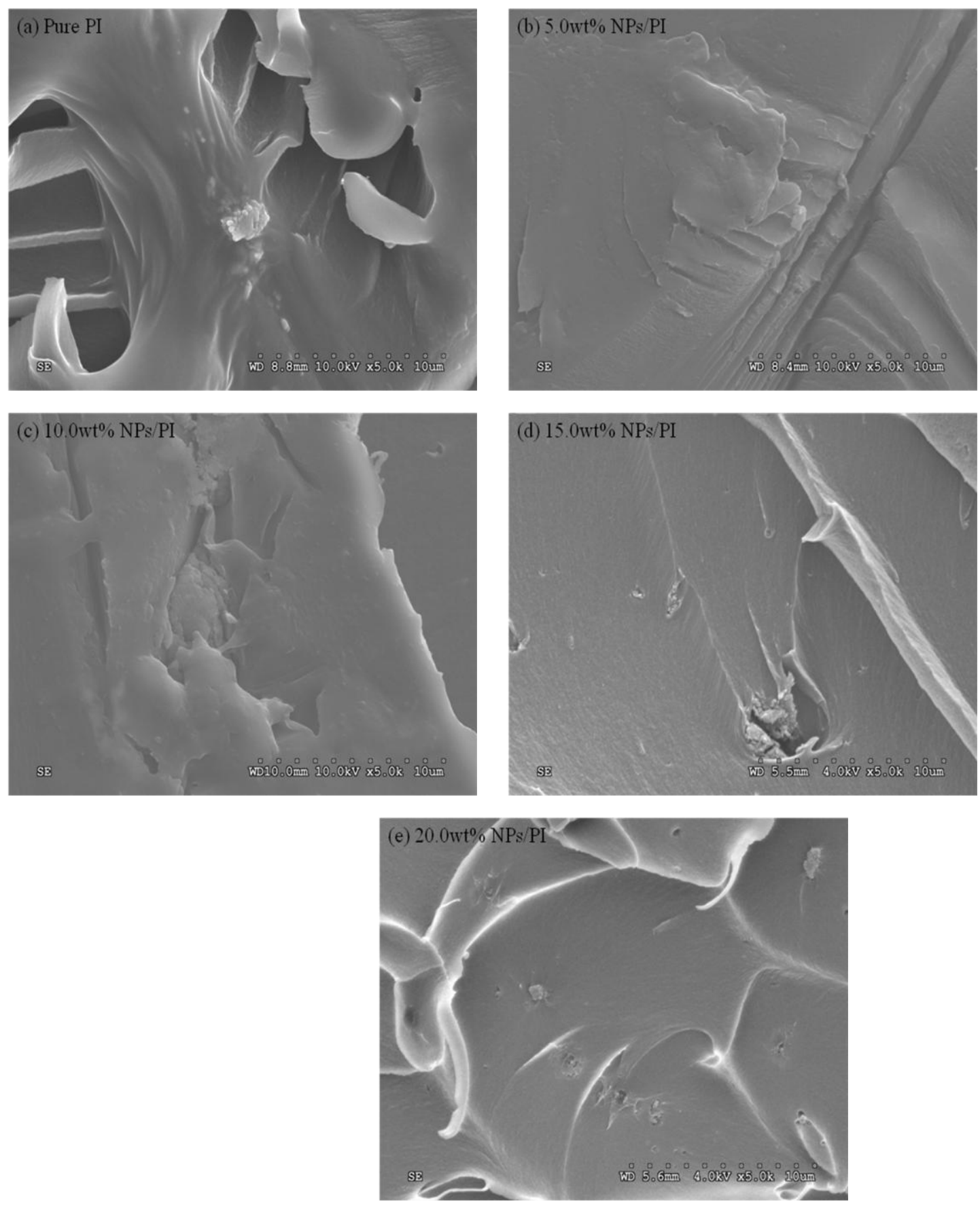

Fig. 2 SEM images of the cross-section of pure PI and $\mathrm{Fe}_{3} \mathrm{O}_{4} / \mathrm{PI}$ nanocomposites films with a $\mathrm{Fe}_{3} \mathrm{O}_{4}$ nanoparticle loading of (a) 0.0, (b) 5.0, (c) 10.0, (d) 15.0, and (e) $20.0 \mathrm{wt} \%$. 
The major issues occurred during the fabrication of matrix films were the surface effect, physical properties of the polymer, particle agglomeration and polymer/particle interactions.[41] Fig. 1 and Fig. 2 show the SEM micrographs of the surface and the cross-section of the nanocomposite films with different nanoparticle loadings, respectively. These indicate that the $\mathrm{Fe}_{3} \mathrm{O}_{4}$ NPs are uniformly distributed in the films surface and cross-section. Fig. 1(d) shows slight agglomeration of the nanoparticles as the particle loading is increased to $15.0 \mathrm{wt} \%$. The agglomeration was attributed to the magnetic dipole-dipole interactions (also called the dipolar coupling, direct interaction between two magnetic dipoles) between the $\mathrm{Fe}_{3} \mathrm{O}_{4}$ NPs. [42] The cross-section SEM images of the $\mathrm{Fe}_{3} \mathrm{O}_{4} / \mathrm{PI}$ nanocomposite films show that the contact between the polymer matrix and the nanofillers was improved. The results also demonstrated a uniform distribution of the $\mathrm{Fe}_{3} \mathrm{O}_{4}$ NPs in PI. To some degree, the surface of nanocomposite films is not as smooth as that of pure PI films since the motion of polymer chains was restricted by the introduced nanoparticles. Under such circumstances, the polymer chains were less patterned than pure PI and thus showed a rougher surface.[43]

\subsection{FT-IR Analysis}

Fig. 3 shows the FT-IR spectra of pure PI and its $\mathrm{Fe}_{3} \mathrm{O}_{4}$ nanocomposite films. The absorption band at $2959 \mathrm{~cm}^{-1}$ was assigned to the aromatic $\mathrm{C}-\mathrm{H}$ stretch of methyl groups. The bands shown at 1782 and $1716 \mathrm{~cm}^{-1}$ were attributed to the symmetric and asymmetric stretching of the $\mathrm{C}=\mathrm{O}$ in the imide group, respectively. The benzophenone $\mathrm{C}=\mathrm{O}$ stretching was observed at $1668 \mathrm{~cm}^{-}$

1. The bands at 1506 and $1482 \mathrm{~cm}^{-1}$ were assigned to the aromatic stretching of the 
para-disubstituted phenyl group. The 1361 and $1086 \mathrm{~cm}^{-1}$ absorption bands were attributed to the stretching of the $\mathrm{C}-\mathrm{N}-\mathrm{C}$ of the imide 5-membered ring.[44] The 1,2,4-trisubstitude of the benzene structure was observed at 864,827 , and $714 \mathrm{~cm}^{-1}$.[43] Compared to the FT-IR spectrum of pure PI, no additional bands were observed in the spectra of $\mathrm{Fe}_{3} \mathrm{O}_{4} / \mathrm{PI}$ nanocomposite films. All the observed bands in the FT-IR spectra confirmed that the molecular structure of PI was well maintained after dissolving in DMF and being casted into films. This indicates that the nanoparticles and PI matrix were physically entangled together to form the nanocomposites, rather than form chemical bonding.

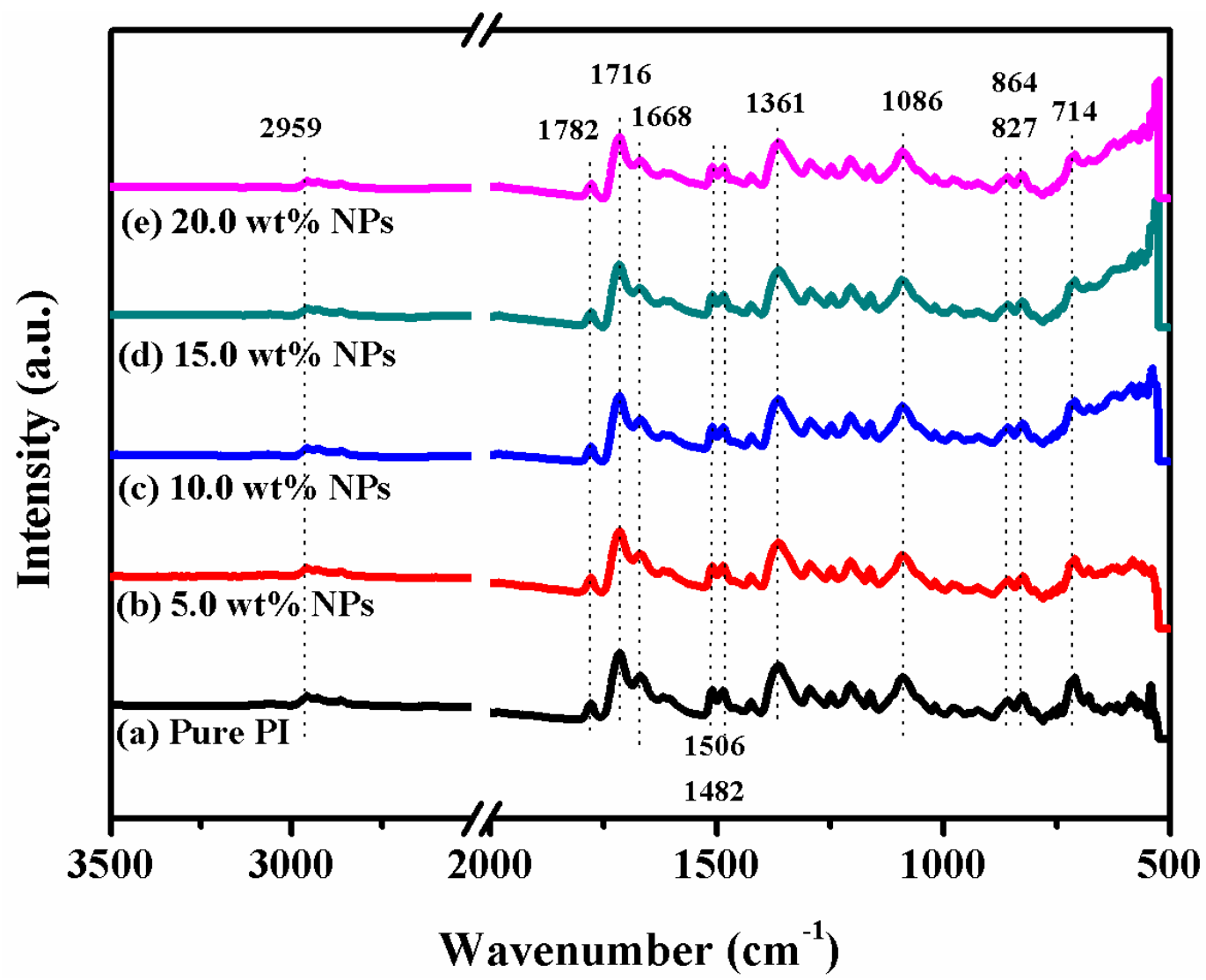

Fig. 3 FT-IR spectra of pure PI and its $\mathrm{Fe}_{3} \mathrm{O}_{4}$ nanocomposite films with a $\mathrm{Fe}_{3} \mathrm{O}_{4}$ nanoparticle loading of (a) 0.0 , (b) 5.0, (c) 10.0 (d) 15.0 , and (e) $20.0 \mathrm{wt} \%$. 


\subsection{XRD Analysis}

Fig. 4 shows the XRD patterns of pure PI, $\mathrm{Fe}_{3} \mathrm{O}_{4} \mathrm{NPs}$, and the $\mathrm{Fe}_{3} \mathrm{O}_{4} / \mathrm{PI}$ nanocomposites films with different $\mathrm{Fe}_{3} \mathrm{O}_{4}$ nanoparticle loadings. For pure PI, only a very broad peak was observed in the range $2 \theta=15-22^{\circ}$ and this wide peak was due to a polyimide amorphous phase.[45] This broad peak was diminished as the $\mathrm{Fe}_{3} \mathrm{O}_{4}$ NPs loading increased because of the reduced proportion of the amorphous PI presented. Meanwhile, in the $\mathrm{Fe}_{3} \mathrm{O}_{4} / \mathrm{PI}$ nanocomposites films, the diffraction peaks of $\mathrm{Fe}_{3} \mathrm{O}_{4}$ can be observed at $2 \theta=35,43$ and $62^{\circ}$, and become more notable with increasing the $\mathrm{Fe}_{3} \mathrm{O}_{4}$ nanoparticle loading. These peaks are assigned to the corresponding (3-1-1), (4-0-0) and (4-4-0) planes of crystalline $\mathrm{Fe}_{3} \mathrm{O}_{4}$, respectively.[46] The d spacing value of all the samples can be calculated using Bragg's Law[47]. The PI peak was located at $2 \theta=15.65 .68 \AA$. The average grain size (L) is estimated from the Debye-Scherrer Equation, as shown in Equation (1):[48]

$$
L=\frac{\kappa \lambda}{\beta \cos \theta}
$$

where the constant $\kappa$ is $0.94, \beta$ is the full width of the peak at half maximum height (FWHM), $\lambda$ is the wavelength of $\mathrm{Cu}-\mathrm{K} \alpha$ radiation, and $L$ is the average diameter of the crystallite. The peak at $2 \theta=35^{\circ}$ is used to estimate the particle size. The calculated values are about $8.7,6.1,5.7$ and $7.1 \mathrm{~nm}$ for the different NPs loadings from 5.0-20.0 wt\%. 


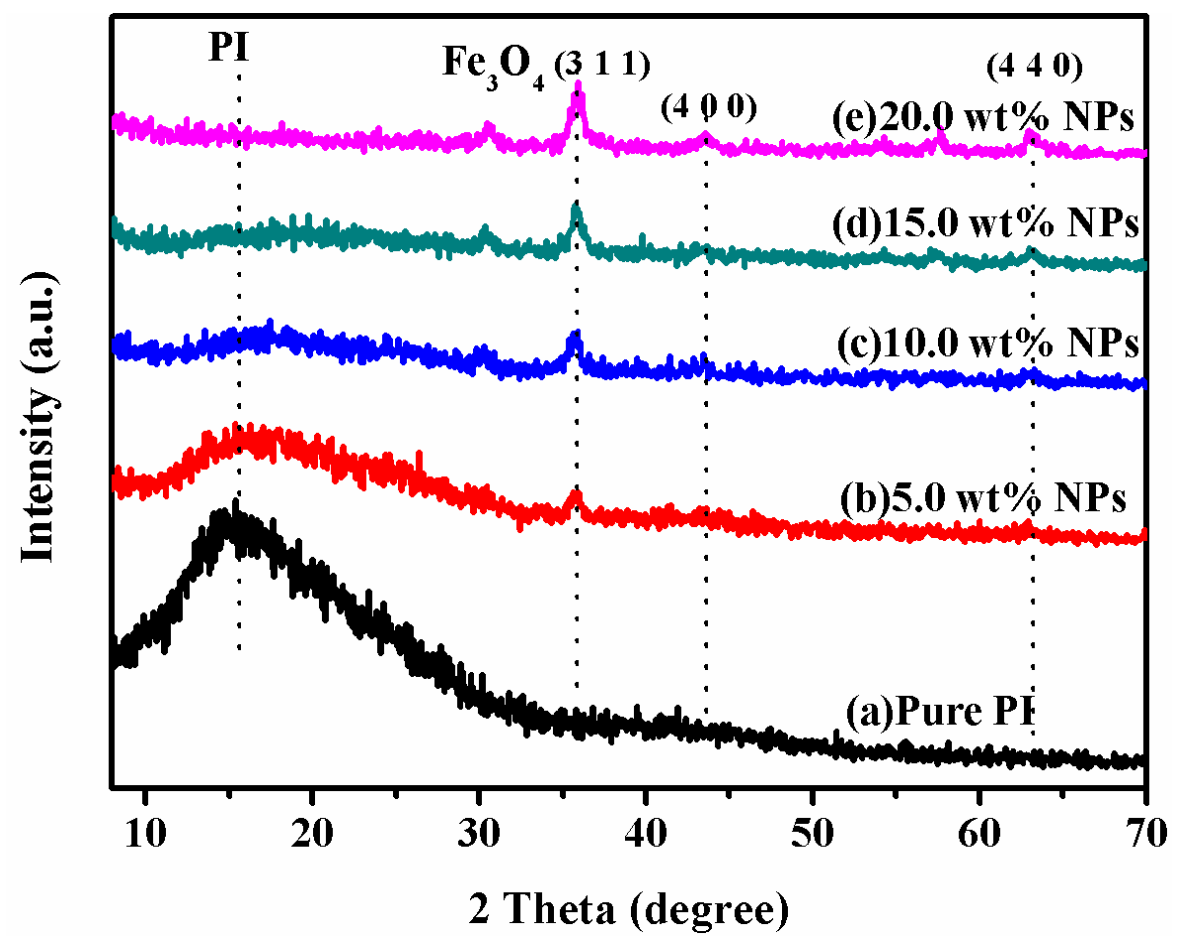

Fig. 4 XRD patterns of pure PI and $\mathrm{Fe}_{3} \mathrm{O}_{4} / \mathrm{PI}$ nanocomposites films with different $\mathrm{Fe}_{3} \mathrm{O}_{4}$ nanoparticle loadings: (a) 0.0, (b) 5.0 (c) 10.0, (d) 15.0, and (e) $20.0 \mathrm{wt} \%$.

\subsection{Optical Properties (UV-Vis)}

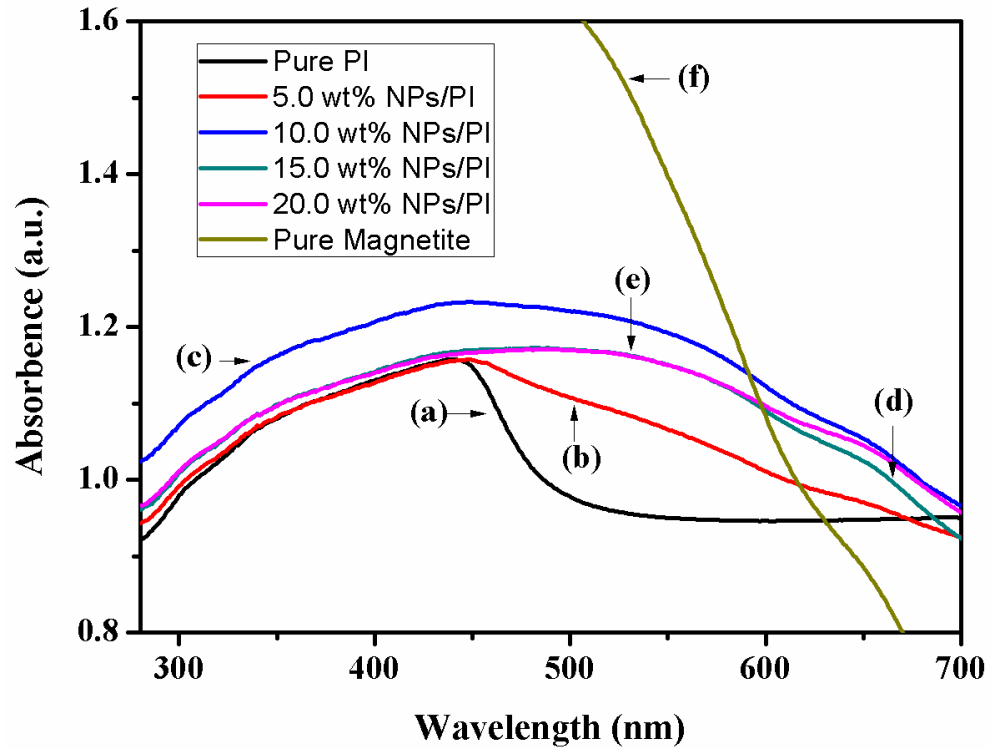

Fig. 5 UV-Vis diffuse reflectance spectra of pure PI, pure $\mathrm{Fe}_{3} \mathrm{O}_{4}$ and $\mathrm{Fe}_{3} \mathrm{O}_{4} / \mathrm{PI}$ nanocomposite films with a $\mathrm{Fe}_{3} \mathrm{O}_{4}$ nanoparticle loading of (a) 0.0, (b) 5.0 (c) 10.0 (d) 15.0 (e) 20.0 and (f) 100 wt $\%$. 
The optical property is an important aspect to be considered for the applications of materials in electronic devices[49, 50] and photo catalysis.[51, 52] Ultraviolet-Visible diffuse reflectance spectroscopy (UV-Vis DRS) has been widely used for the measurement of the UV-Vis absorption edge ( $\lambda$ edge, the transition between strong short-wavelength and weak long-wavelength absorption in the spectrum of a solid sample).[53] The spectral position of this absorption edge is determined by the energy difference between the valence state and the conduction state. The band gap ( $\left.\mathrm{E}_{\mathrm{g}}{ }^{\text {opt}}\right)$ can be obtained from Equation (2) based on the onset of UV-Vis diffuse reflectance spectra of the samples:[54]

$$
\mathrm{E}_{\mathrm{g}}{ }^{\mathrm{opt}}(\mathrm{eV})=1240 / \lambda_{\text {edge }}(\mathrm{nm})
$$

where $\mathrm{E}_{\mathrm{g}}{ }^{\mathrm{ppt}}$ is the optical band gap (difference between the valence band and the conduction band) and the number 1240 is obtained from the relationship between frequency and wavelength as described following Equation (3):[42]

$$
\mathrm{E}(\mathrm{eV})=\mathrm{h} \gamma=\mathrm{hc} / \lambda
$$

where $\mathrm{h}$ is Planck's constant, $\mathrm{c}$ is the speed of light in a vacuum and $\mathrm{e}$ is the electron charge, the unit of $\lambda$ is meter, and then 1240 can be obtained from hc. 
Table 1 Absorption edge and optical band gap of pure PI and $\mathrm{Fe}_{3} \mathrm{O}_{4} / \mathrm{PI}$ nanocomposite films with a $\mathrm{Fe}_{3} \mathrm{O}_{4}$ nanoparticle loading of $5.0 \%, 10.0 \%, 15.0 \%$, and $20.0 \%$

\begin{tabular}{|c|c|c|}
\hline $\begin{array}{c}\text { Samples with } \\
\text { different Fe3O4 } \\
\text { NPs loadings }\end{array}$ & $\begin{array}{c}\text { Absorption edge of } \\
\mathrm{PI}\left(\lambda_{\text {edge }, \mathrm{nm}}\right)\end{array}$ & $\begin{array}{c}\text { Optical band gap of } \\
\mathrm{PI}\left(\mathrm{E}_{\mathrm{g}}{ }^{\text {opt }}, \mathrm{eV}\right)\end{array}$ \\
\hline $0.0 \%$ & 447 & 2.77 \\
\hline $5.0 \%$ & 443 & 2.80 \\
\hline $10.0 \%$ & 458 & 2.70 \\
\hline $15.0 \%$ & 470 & 2.64 \\
\hline $20.0 \%$ & 472 & 2.62 \\
\hline
\end{tabular}

Fig. 5 shows the UV-Vis diffused reflectance spectra of pure PI and its $\mathrm{Fe}_{3} \mathrm{O}_{4}$ nanocomposite films with different $\mathrm{Fe}_{3} \mathrm{O}_{4}$ loadings. According to Equation (2), the $\lambda$ edge of pure PI calculated by the onset of the UV-Vis DRS in Fig. 4 was $447 \mathrm{~nm}$ and the $\mathrm{E}_{\mathrm{g}}{ }^{\text {opt }}$ of pure PI was $2.77 \mathrm{eV}$. The calculated $\mathrm{E}_{\mathrm{g}}{ }^{\text {opt }}$ of pure PI was consistent with the results investigated previously in the PI ( $\lambda$ edge is in $400-550 \mathrm{~nm}$ )[55] and in the pure PI.[56] And this was attributed to the transition of electron from $\pi$ to $\pi *$ in the phenyl ring. [57] The $\lambda$ edge and the corresponding calculated $\mathrm{E}_{\mathrm{g}}{ }^{\text {opt }}$ for the $\mathrm{Fe}_{3} \mathrm{O}_{4} / \mathrm{PI}$ nanocomposites films with a $\mathrm{Fe}_{3} \mathrm{O}_{4}$ nanoparticle loading of 5.0, 10.0, 15.0 and $20.0 \mathrm{wt} \%$ obtained from UV-Vis DRS are listed in Table 1. From Table 1, the band gap of PI decreases with increasing the $\mathrm{Fe}_{3} \mathrm{O}_{4}$ loading, which was due to the interaction between $\mathrm{Fe}_{3} \mathrm{O}_{4}$ NPs and PI polymer backbone. 


\subsection{DSC Analysis}

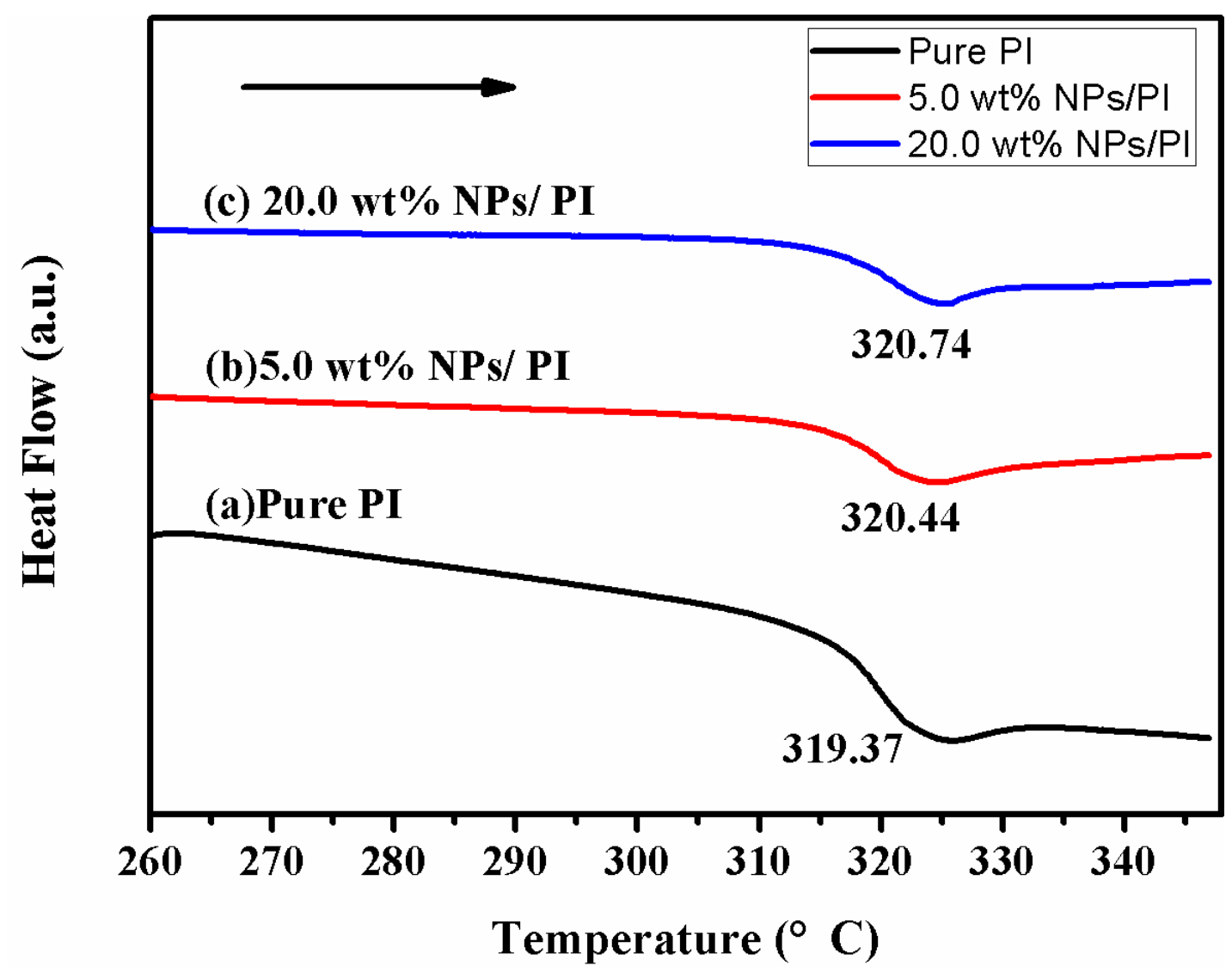

Fig. 6 DSC thermograms of pure $\mathrm{PI}$ and its $\mathrm{Fe}_{3} \mathrm{O}_{4}$ nanocomposites films with a $\mathrm{Fe}_{3} \mathrm{O}_{4}$ nanoparticle loading of (a) 0.0 , (b) 5.0 , and (c) $20.0 \mathrm{wt} \%$.

The glass transition temperature $\left(\mathrm{T}_{\mathrm{g}}\right)$ of the films was measured with differential scanning calorimetry (DSC, TA Instruments). The film samples were cut into small pieces, weighed and placed into a $\mathrm{T}_{\text {zero }}$ Pan (TA Instruments). The weight of each sample was about 5-10 mg. Then, the sample was heated from 25 to $350^{\circ} \mathrm{C}$ with a nitrogen flow rate of $20 \mathrm{~mL} / \mathrm{min}$ and a heating rate of $10^{\circ} \mathrm{C} / \mathrm{min}$ in the first cycle to remove the thermal history. Then, the sample was naturally cooled down to $40{ }^{\circ} \mathrm{C}$ and heated again to $350{ }^{\circ} \mathrm{C}$ with the same conditions as the first scan. The 
$\mathrm{T}_{\mathrm{g}}$ of the sample was determined as the midpoint temperature of the transition region in the second heating cycle. Fig. 6 shows the DSC curves of pure PI and its $\mathrm{Fe}_{3} \mathrm{O}_{4}$ nanocomposites films. The dip observed at around $320^{\circ} \mathrm{C}$ indicates the glass transition temperature. It is evident that $\mathrm{T}_{\mathrm{g}}$ was slightly increased with increasing the $\mathrm{Fe}_{3} \mathrm{O}_{4}$ nanoparticle loading. The $\mathrm{T}_{\mathrm{g}}$ for pure PI was $319.37{ }^{\circ} \mathrm{C}$ and increased to $320.44{ }^{\circ} \mathrm{C}$ for the nanocomposites containing $5.0 \mathrm{wt} \% \mathrm{Fe}_{3} \mathrm{O}_{4}$ NPs and further to $320.74{ }^{\circ} \mathrm{C}$ for the nanocomposites containing 20.0 wt $\% \mathrm{Fe}_{3} \mathrm{O}_{4}$ NPs. The observed $\mathrm{T}_{\mathrm{g}}$ of pure PI was consistent with the results investigated previously in the mixed matrix membranes for $\mathrm{O}_{2} / \mathrm{N}_{2}$ gas separation ( $\mathrm{T}_{\mathrm{g}}$ of pure $\mathrm{PI}$ is $320^{\circ} \mathrm{C}$ ).[58] A similar phenomenon was observed in polymer/clay nanocomposites, where the DSC results showed a continuous increase in $\mathrm{T}_{\mathrm{g}}$ with the addition of the $\mathrm{Fe}_{3} \mathrm{O}_{4}$ content.[59] The increase in $\mathrm{T}_{\mathrm{g}}$ observed in the PI nanocomposites with increasing the nanoparticle loading was attributed to the interactions between $\mathrm{Fe}_{3} \mathrm{O}_{4} \mathrm{NPs}$, PI matrix and the confinement of PI polymer chains, which restricted the segmental motions of the polymer chains at the organic-inorganic interface.[60]

\subsection{Thermo Gravimetric Analysis (TGA)}

The thermal stability of pure PI and its $\mathrm{Fe}_{3} \mathrm{O}_{4}$ nanocomposite films with different $\mathrm{Fe}_{3} \mathrm{O}_{4}$ loadings was studied by thermo gravimetric analysis. Fig. 7 shows the weight percentage change of the material as a function of temperature. Table 2 shows the summarized thermal properties of pure $\mathrm{PI}$ and its $\mathrm{Fe}_{3} \mathrm{O}_{4}$ nanocomposites films. For all the nanocomposites, there is only one main degradation (weight loss) stage associated with the breaking of the cross-linked network in 
polymer and the release of moisture and organic solvent residue entangled in the PI polymer chains.[61] From the onset decomposition temperature summarized in Table 2, the decomposition temperature was firstly increased with increasing the $\mathrm{Fe}_{3} \mathrm{O}_{4}$ nanoparticle loading (5.0, 10.0 and $15.0 \mathrm{wt} \%)$, then decreased $(20.0 \mathrm{wt} \%)$ but still lower than that of pure PI. The enhanced thermal stability is associated with the protection effect of the $\mathrm{Fe}_{3} \mathrm{O}_{4} \mathrm{NPs}$, which could act as a shield and separate the polymer chains from heat.[61] The temperatures to reach $10 \%$ $\left(\mathrm{T}_{\mathrm{d} 10 \%}\right)$ and $15 \%\left(\mathrm{~T}_{\mathrm{d} 15 \%}\right)$ weight loss (only refers to the PI fraction of the nanocomposite films since the $\mathrm{Fe}_{3} \mathrm{O}_{4}$ does not decompose) in TGA tests were usually reported to characterize the thermal stability of a material. The $\mathrm{T}_{\mathrm{d} 10 \%}$ and $\mathrm{T}_{\mathrm{d} 15 \%}$ for pure PI and its $\mathrm{Fe}_{3} \mathrm{O}_{4}$ nanocomposites films with a $\mathrm{Fe}_{3} \mathrm{O}_{4}$ nanoparticle loading of 5.0, 10.0, 15.0 and $20.0 \mathrm{wt} \%$ were also summarized in Table 2. The weight residues of the $\mathrm{Fe}_{3} \mathrm{O}_{4} / \mathrm{PI}$ nanocomposites with an initial $\mathrm{Fe}_{3} \mathrm{O}_{4}$ nanoparticle loading of 5.0, 10.0, 15.0 and $20.0 \mathrm{wt} \%$ at $400{ }^{\circ} \mathrm{C}$ were $94.6,92.8,95.4$ and $96.1 \mathrm{wt} \%$, respectively. The weight residues of the $\mathrm{Fe}_{3} \mathrm{O}_{4} / \mathrm{PI}$ nanocomposites with an initial $\mathrm{Fe}_{3} \mathrm{O}_{4}$ nanoparticle loading of 5.0, 10.0, 15.0 and $20.0 \mathrm{wt} \%$ at $800{ }^{\circ} \mathrm{C}$ were $53.9,52.9,54.7$ and 53.6 wt $\%$. The thermal stability of PI in the temperature range of $300-400{ }^{\circ} \mathrm{C}$ demonstrated the capability to process these nanocomposites within this temperature range.[43] Some differences were observed in the onset decomposition temperature between pure PI and the composites. This indicates that the $\mathrm{Fe}_{3} \mathrm{O}_{4}$ NPs have some positive influences on the thermal stability of the nanocomposites, and the nanoparticles and PI matrix are physically entangled together to form the nanocomposites. 


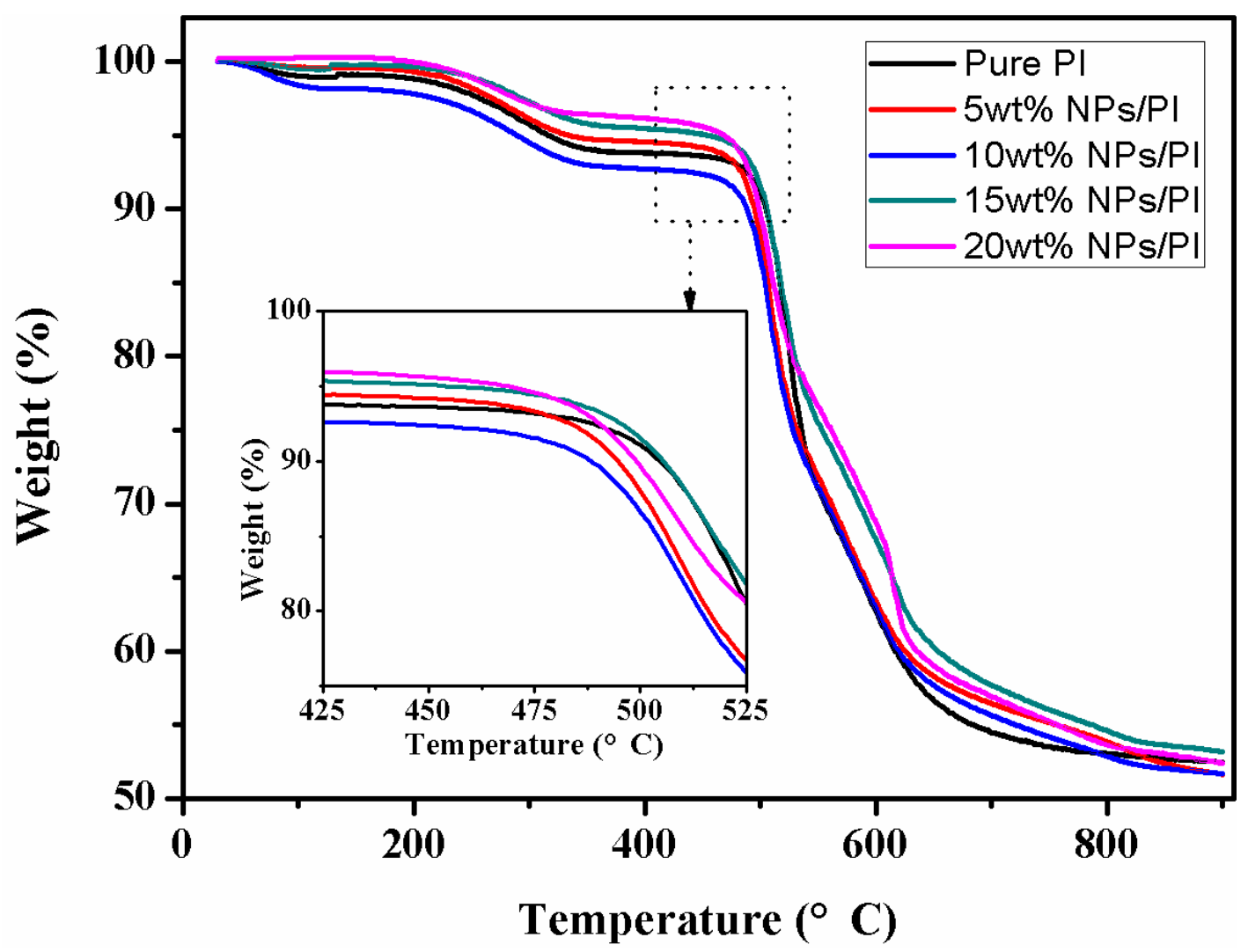

Fig. 7 TGA curves under nitrogen of pure $\mathrm{PI}$ and its $\mathrm{Fe}_{3} \mathrm{O}_{4}$ nanocomposite films with a $\mathrm{Fe}_{3} \mathrm{O}_{4}$ nanoparticle loading of (a) 0.0, (b) 5.0, (c) 10.0, (d) 15.0, and (e) $20.0 \mathrm{wt} \%$.

Table 2 Thermal properties of pure $\mathrm{PI}$ and its $\mathrm{Fe}_{3} \mathrm{O}_{4}$ nanocomposite films with a $\mathrm{Fe}_{3} \mathrm{O}_{4}$ nanoparticle loading of 5.0, 10.0, 15.0, and $20.0 \mathrm{wt} \%$.

\begin{tabular}{|c|c|c|c|c|c|}
\hline $\begin{array}{c}\text { Samples with } \\
\text { different NPs } \\
\text { loadings (wt\%) }\end{array}$ & $\begin{array}{c}\text { Onset } \\
\text { temperature } \\
\left({ }^{\circ} \mathrm{C}\right)\end{array}$ & $\begin{array}{c}10 \mathrm{wt} \% \text { loss } \\
\text { decomposition } \\
\text { temperature } \\
\left({ }^{\circ} \mathrm{C}\right)\end{array}$ & $\begin{array}{c}15 \mathrm{wt} \% \text { loss } \\
\text { decomposition } \\
\text { temperature } \\
\left({ }^{\circ} \mathrm{C}\right)\end{array}$ & $\begin{array}{c}\text { Weight residue } \\
(\mathrm{wt} \%) \text { at } \\
400{ }^{\circ} \mathrm{C}\end{array}$ & $\begin{array}{c}\text { Weight residue } \\
(\mathrm{wt} \%) \text { at } \\
800{ }^{\circ} \mathrm{C}\end{array}$ \\
\hline 0.0 & 502.26 & 504.5 & 517.1 & 93.9 & 53.1 \\
\hline 5.0 & 488.82 & 494.8 & 506.5 & 94.6 & 53.9 \\
\hline 10.0 & 489.19 & 488.5 & 503.9 & 92.8 & 52.9 \\
\hline 15.0 & 495.57 & 505.2 & 517.8 & 95.4 & 54.7 \\
\hline 20.0 & 486.81 & 498.9 & 511.4 & 96.1 & 53.6 \\
\hline
\end{tabular}




\subsection{Contact Angle}

The contact angles of pure PI and its $\mathrm{Fe}_{3} \mathrm{O}_{4}$ nanocomposite films with different $\mathrm{Fe}_{3} \mathrm{O}_{4}$ nanoparticle loadings were measured by the sessile drop method with a contact angle analyzer (SEO 300A by Surface Electro Optics Corporation Ltd., Korea). A total of $3 \mu$ drops of deionized (DI) water was carefully placed on the substrate using a microliter syringe. The drop was viewed using a CCD camera attached to a microscope, and the drop image was digitized and stored in a computer every second during the measurement. The contact angles of each drop were measured five times to obtain an average value. The shape of the drop on the surface did not change significantly during the measurement. All measurements were carried out at room temperature.

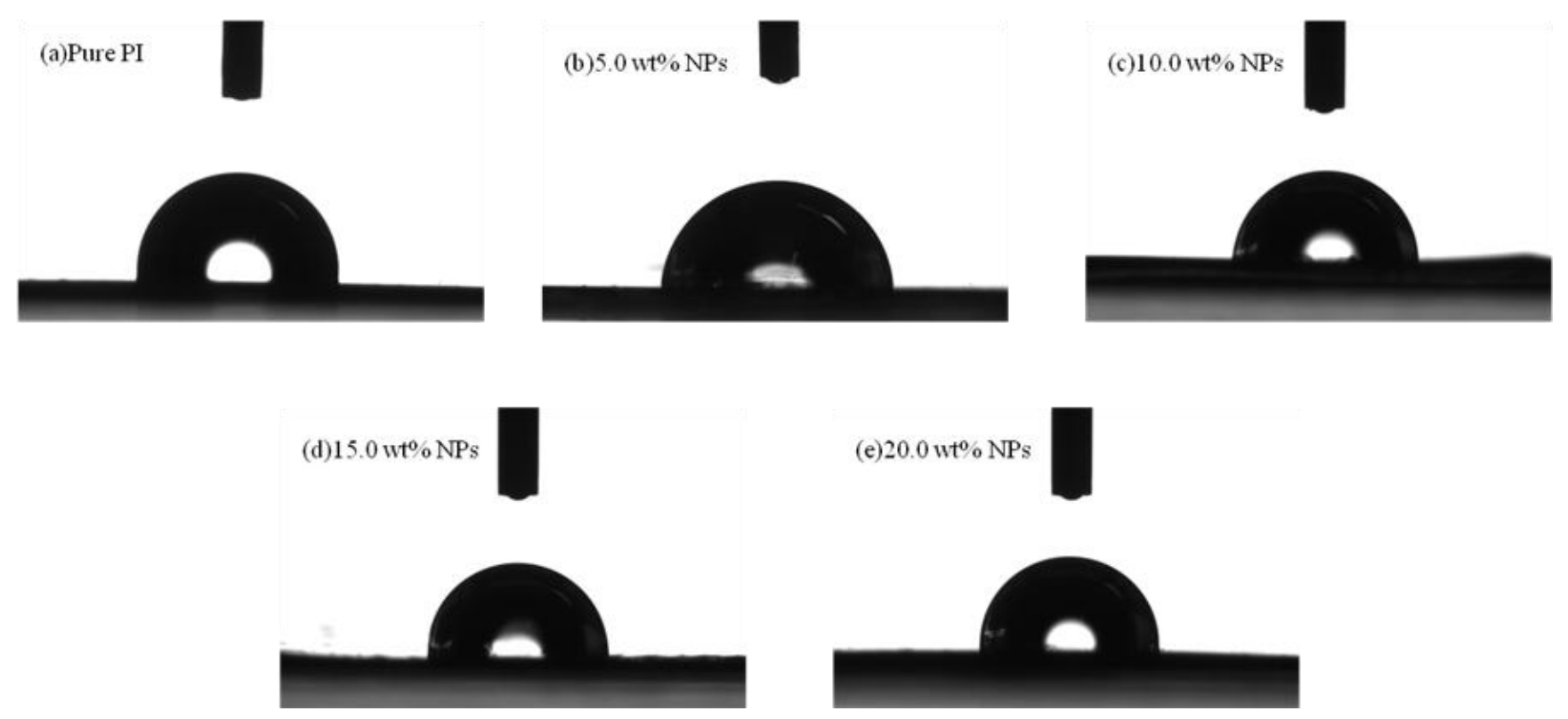

Fig. 8 Contact angle of the $\mathrm{Fe}_{3} \mathrm{O}_{4} / \mathrm{PI}$ nanocomposite films with a $\mathrm{Fe}_{3} \mathrm{O}_{4}$ loading of (a) 0.0, (b) 5.0, (c) 10.0, (d) 15.0, and (e) $20.0 \mathrm{wt} \%$. 
Hydrophilicity of pure $\mathrm{PI}$ and its $\mathrm{Fe}_{3} \mathrm{O}_{4}$ nanocomposites films with different $\mathrm{Fe}_{3} \mathrm{O}_{4}$ loadings is shown in Fig. 8 and summarized in Table 3. The contact angle of pure PI and its $\mathrm{Fe}_{3} \mathrm{O}_{4}$ nanocomposites with an initial $\mathrm{Fe}_{3} \mathrm{O}_{4}$ nanoparticle loading of $0.0,5.0,10.0,15.0$ and $20.0 \mathrm{wt} \%$ were $100.5,90.9,93.6,96.1$ and $99.2^{\circ}$, respectively. It is obvious that the contact angle of pure PI was bigger than that of the $\mathrm{Fe}_{3} \mathrm{O}_{4} / \mathrm{PI}$ nanocomposites films, indicating that the increase in the roughness reduced the contact angles.[62] The decrease of the contact angle was mainly attributed to the increase in the total surface energy of the PI films due to the increased specific surface area induced by roughening.[63] Besides, the contact angle of the $\mathrm{Fe}_{3} \mathrm{O}_{4} / \mathrm{PI}$ nanocomposites films increased with increasing the loading of $\mathrm{Fe}_{3} \mathrm{O}_{4}$. The hydrophilicity of PI films was reduced due to the presence of more $\mathrm{Fe}_{3} \mathrm{O}_{4}$ nanoparticles on the film surface. More magnetic nanoparticle attachment leads to a higher contact angles. This could be due to the relative hydrophobicity of the nanoparticle surface. A similar result was reported for the magnetic field responsive nanofiltration membranes.[64]

Table 3 Contact angles of pure $\mathrm{PI}$ and $\mathrm{Fe}_{3} \mathrm{O}_{4} / \mathrm{PI}$ nanocomposite films with a $\mathrm{Fe}_{3} \mathrm{O}_{4}$ nanoparticle loading of $5.0 \%, 10.0 \%, 15.0 \%$, and $20.0 \%$

\begin{tabular}{|c|c|}
\hline $\begin{array}{c}\text { Samples with different } \mathrm{Fe}_{3} \mathrm{O}_{4} \mathrm{NPs} \\
\text { loadings (wt\%) }\end{array}$ & $\begin{array}{c}\text { Contact angle } \\
\left({ }^{\circ}\right)\end{array}$ \\
\hline 0.0 & 100.5 \\
\hline 5.0 & 90.9 \\
\hline 10.0 & 93.6 \\
\hline 15.0 & 96.1 \\
\hline 20.0 & 99.2 \\
\hline
\end{tabular}




\subsection{Dielectric Properties}
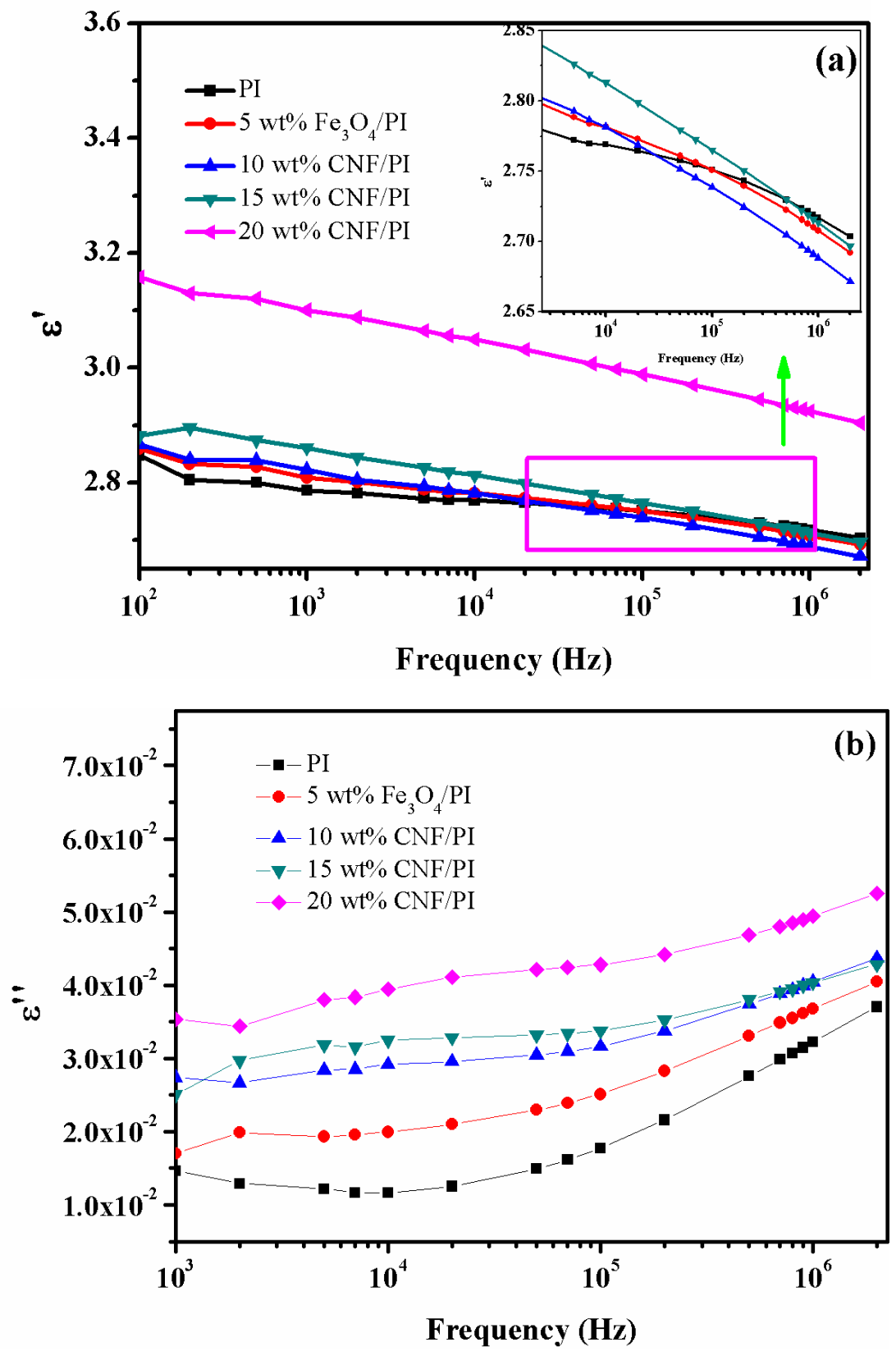


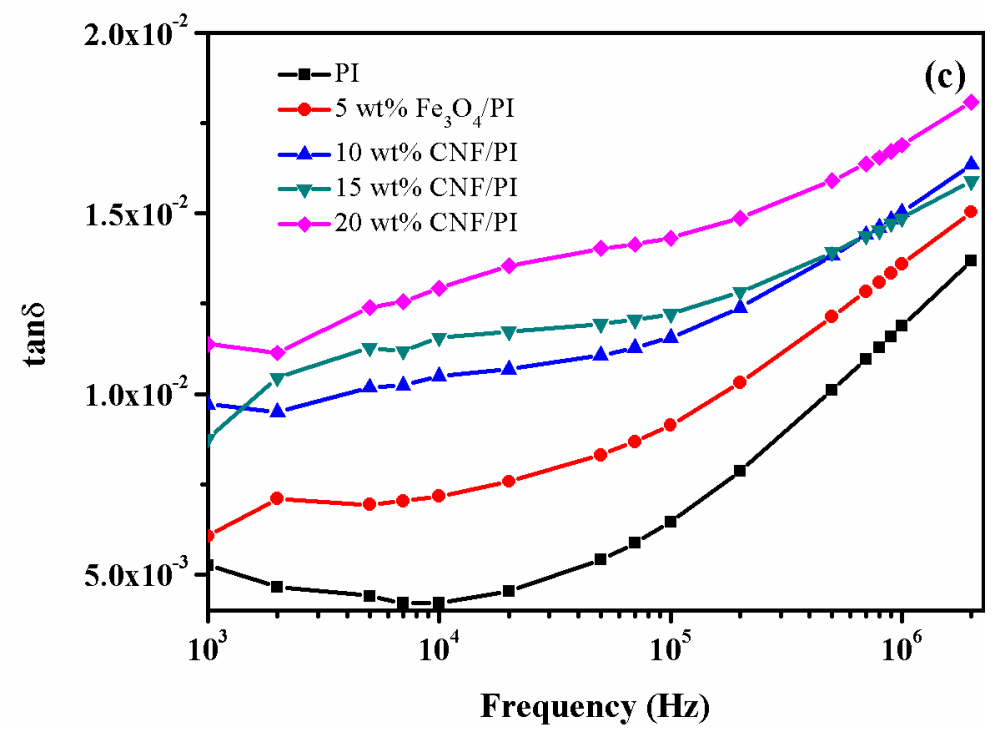

Fig. 9 (a) Real permittivity $\left(\varepsilon^{\prime}\right)$, (b) imaginary permittivity $\left(\varepsilon^{\prime \prime}\right)$ and (c) dielectric loss ( $\tan \delta$, where $\tan \delta=\varepsilon^{\prime \prime} / \varepsilon^{\prime}$ ) as a function of frequency for pure PI and its $\mathrm{Fe}_{3} \mathrm{O}_{4}$ nanocomposite films within the frequency range of 20 to $2 \times 10^{6} \mathrm{~Hz}$ at room temperature.

Fig. 9 shows the real permittivity $\left(\varepsilon^{\prime}\right.$, Fig. 9(a)), imaginary permittivity ( $\varepsilon^{\prime \prime}$, Fig. 9(b)), and dielectric loss tangent $\left(\tan \delta\right.$, where $\tan \delta=\varepsilon^{\prime \prime} / \varepsilon^{\prime}$, Fig. 9(c)) as a function of frequency at room temperature for pure $\mathrm{PI}$ and its $\mathrm{Fe}_{3} \mathrm{O}_{4}$ nanocomposite films with a $\mathrm{Fe}_{3} \mathrm{O}_{4}$ nanoparticle loading of 5.0, 10.0, 15.0, and $20.0 \mathrm{wt} \%$. In Fig. 9(a), all these samples exhibited positive real permittivity within the measured frequency range and the $\varepsilon^{\prime}$ was decreased with increasing the frequency from $10^{2}$ to $10^{6} \mathrm{~Hz}$. The decrease of $\varepsilon^{\prime}$ at high frequency was attributed to the dipolar groups, which cannot follow the speed of the alternating electric field (dielectric relaxation phenomena).[61] The inset of Fig. 9(a) shows the positive $\varepsilon^{\prime}$ value within the frequency range from $10^{4}$ to $10^{6} \mathrm{~Hz}$. Generally, the frequency-dependent dielectric properties of the nanocomposites are strongly related to the interfacial polarization between the hosting polymer matrix and the nanoparticles. This phenomenon is called as the Maxwell - Wagner-Sillars 
(MWS) polarization effect, in which the charge carriers are accumulated at the inner dielectric boundary layers or at the interfaces within composites matrix.[54, 65] The $\mathrm{Fe}_{3} \mathrm{O}_{4} / \mathrm{PI}$ nanocomposite films with a $\mathrm{Fe}_{3} \mathrm{O}_{4}$ nanoparticle loading of $20.0 \mathrm{wt} \%$ had the highest value of $\varepsilon^{\prime}$ compared with other.

Fig 9(b) shows the $\varepsilon^{\prime \prime}$ of pure $\mathrm{PI}$ and its $\mathrm{Fe}_{3} \mathrm{O}_{4}$ nanocomposites films with a $\mathrm{Fe}_{3} \mathrm{O}_{4}$ nanoparticle loading of 5.0, 10.0, 15.0, and $20.0 \mathrm{wt} \%$. The $\varepsilon^{\prime \prime}$ of pure PI was decreased with increasing the frequency at low frequency ranges $\left(<10^{4} \mathrm{~Hz}\right)$, then increased after $10^{4} \mathrm{~Hz}$. The $\varepsilon^{\prime \prime}$ of the $\mathrm{Fe}_{3} \mathrm{O}_{4} / \mathrm{PI}$ nanocomposites with a $\mathrm{Fe}_{3} \mathrm{O}_{4}$ nanoparticle loading of 10.0 and 20.0 wt $\%$ exhibited a similar decrease then increase trend as that of pure PI. The $\varepsilon$ " value of the $15.0 \mathrm{wt} \%$ $\mathrm{Fe}_{3} \mathrm{O}_{4} / \mathrm{PI}$ nanocomposites was increased monotonically with increasing the frequency from $10^{2}$ to $10^{6} \mathrm{~Hz}$. However the $\varepsilon^{\prime \prime}$ value of the $5.0 \% \mathrm{Fe}_{3} \mathrm{O}_{4} / \mathrm{PI}$ nanocomposites was increased and then decreased at low frequency range $\left(<10^{4} \mathrm{~Hz}\right)$, then increased at high frequency range $\left(>10^{4} \mathrm{~Hz}\right)$.

Fig. 9(c) shows the frequency-dependent tan $\delta$ for pure PI and its $\mathrm{Fe}_{3} \mathrm{O}_{4}$ nanocomposites films with a $\mathrm{Fe}_{3} \mathrm{O}_{4}$ nanoparticle loading of 5.0, 10.0, 15.0, and $20.0 \mathrm{wt} \%$. The tan $\delta$ patterns for different loading nanocomposites were similar to the $\varepsilon^{\prime \prime}$ pattern for different loading nanocomposites. And $\tan \delta$ was increased monotonically after $10^{4} \mathrm{~Hz}$ with increasing the frequency. The observed higher $\tan \delta$ of the nanocomposites than that of pure PI is related to the free charge motion difference, indicating that there was an interfacial polarization in the nanocomposites.[61] The composites with low energy loss have a potential application in the microelectronic devices. 


\subsection{Magnetic Property}

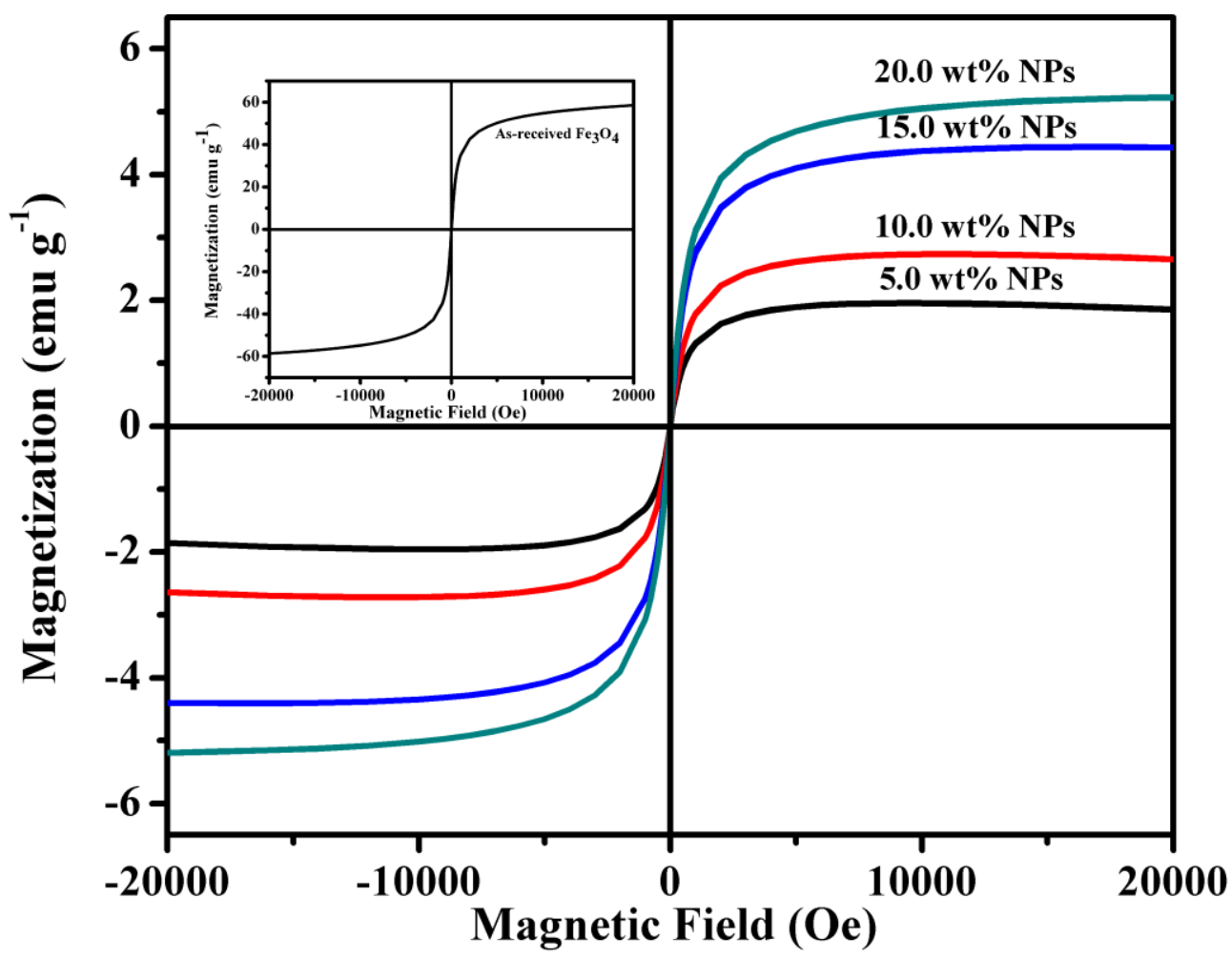

Fig. 10 Room temperature hysteresis loops of the $\mathrm{Fe}_{3} \mathrm{O}_{4} / \mathrm{PI}$ nanocomposite films with a $\mathrm{Fe}_{3} \mathrm{O}_{4}$ nanoparticle loading of (a) 0.0, (b) 5.0, (c) 10.0, (d) 15.0, and (e) $20.0 \mathrm{wt} \%$. Inset shows the hysteresis loop of pure nanoparticles.

Fig.10 shows the room temperature magnetic hysteresis loops of $\mathrm{Fe}_{3} \mathrm{O}_{4} / \mathrm{PI}$ nanocomposite films with a $\mathrm{Fe}_{3} \mathrm{O}_{4}$ nanoparticle loading of 5.0, 10.0, 15.0, and $20.0 \mathrm{wt} \%$. The insert of Fig. 10 shows the hysteresis loop of the as-received pure $\mathrm{Fe}_{3} \mathrm{O}_{4}$ NPs. The saturation magnetization $(M s)$ is defined as the state, at which point the magnetic field cannot increase the magnetization of the material further.[66] The pure PI was observed to be non-magnetic as expected, whereas the curves of the others showed no hysteresis loops. The $M s$ of the as-received $\mathrm{Fe}_{3} \mathrm{O}_{4} \mathrm{NPs}$ was not reached even at high magnetic field and was determined by the extrapolated saturation 
magnetization obtained from the intercept of $\mathrm{M} \approx \mathrm{H}^{-1}$ at high field.[67] $\mathrm{The}^{\mathrm{Fe}} \mathrm{O}_{3} \mathrm{O}_{4} \mathrm{NP}$ did not show hysteresis loop with zero coercivity, indicating the superparamagnetic behavior at room temperature. The calculated $M s$ of the as-received $\mathrm{Fe}_{3} \mathrm{O}_{4} \mathrm{NPs}$ was 58.09 emu g${ }^{-1}$. The $M_{S}$ values of the PI/ $\mathrm{Fe}_{3} \mathrm{O}_{4}$ films with a particle loading of 5, 10, 15 and $20 \mathrm{wt} \%$ were observed to be saturated at a lower field and were 1.96, 2.72, 4.43 and $5.21 \mathrm{emu} \mathrm{g}^{-1}$, respectively. The $M s$ of the PI/ $\mathrm{Fe}_{3} \mathrm{O}_{4}$ films was increased with increasing the $\mathrm{Fe}_{3} \mathrm{O}_{4}$ NPs loading, which is due to the increased proportion of the magnetic particles. In addition, the magnetization was saturated more rapidly in the $\mathrm{PI} / \mathrm{Fe}_{3} \mathrm{O}_{4}$ films with a lower NP loading. An infinitesimal coercivity was observed in all the samples, indicating a superparamagnetic behavior of the NPs disregard of the polymer matrix.[68]

\subsection{Swelling Property}

Pure PI and its nanocomposites films were dried under vacuum at $140{ }^{\circ} \mathrm{C}$ for $48 \mathrm{~h}$ and pre-weighed, then immersed in n-hexadecane for the swelling test. Each dried film was swollen in n-hexadecane at $50{ }^{\circ} \mathrm{C}$ to achieve equilibrium swelling. The degree of swelling of films was measured after 4, 8, 12, 16, 20, 24, 48 and 72 hours. The swollen sample was taken out and immediately weighed after drying the samples with tissue papers. The degree of swelling was calculated from the difference between the wet weight after sorption equilibrium and the original dry weight.[69]

Fig. 11 shows the degree of swelling of $\mathrm{Fe}_{3} \mathrm{O}_{4} / \mathrm{PI}$ nanocomposites films with different $\mathrm{Fe}_{3} \mathrm{O}_{4}$ 
NPs loadings. The degree of swelling of the $\mathrm{Fe}_{3} \mathrm{O}_{4} / \mathrm{PI}$ nanocomposites films was increased with increasing the $\mathrm{Fe}_{3} \mathrm{O}_{4}$ loading and swelling time. This can be explained by the physical entanglement of the NPs in between the PI matrix. As increasing the $\mathrm{Fe}_{3} \mathrm{O}_{4}$ loading, the NPs involved in the PI matrix were agglomerated strongly than lower loadings, and the degree of swelling started to increase.

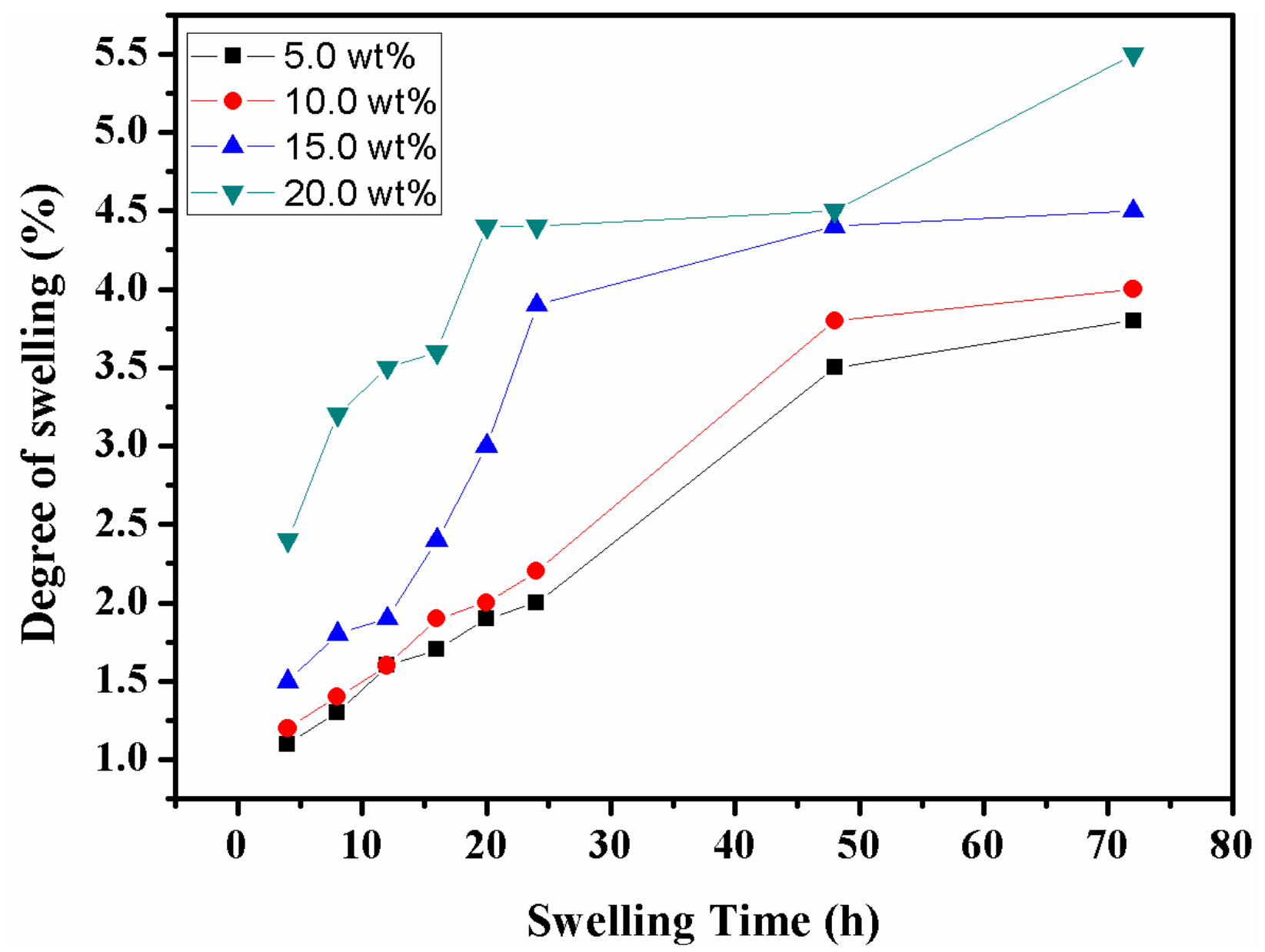

Fig.11 Degree of swelling of $\mathrm{Fe}_{3} \mathrm{O}_{4} / \mathrm{PI}$ nanocomposite films with a $\mathrm{Fe}_{3} \mathrm{O}_{4}$ nanoparticle loading of (a) 0.0 , (b) 5.0, (c) 10.0, (d) 15.0, and (e) $20.0 \mathrm{wt} \%$. 


\section{Conclusion}

A series of $\mathrm{Fe}_{3} \mathrm{O}_{4} /$ polyimide nanocomposites have been prepared in this research. The FT-IR characterization demonstrated the physical entanglement between the $\mathrm{Fe}_{3} \mathrm{O}_{4} \mathrm{NPs}$ and polyimide matrix. The band gap decrease was obtained via the UV-Vis experiment. TGA and DSC test results showed that the thermal stability was improved with increasing the $\mathrm{Fe}_{3} \mathrm{O}_{4} \mathrm{NPs}$ loading. The contact angle test indicated that more magnetic nanoparticles entangled in the PI film would increase the property of hydrophobicity of the nanocomposites. With the introduction of $\mathrm{Fe}_{3} \mathrm{O}_{4}$ NPs, dielectric property was also improved for reducing the energy loss, indicated a potential electric application in the micron electric instruments. The magnetic property has been improved and the $20 \%$ can even reach 5.21 emu.g $^{-1}$, indicating the potential application for magnetic area.

\section{Acknowledgement}

The financial supports from National Science Foundation (NSF, CMMI 10-30755 and 13-14486) were kindly acknowledged.

\section{References and Notes}


[1] D. Ding, H. Wei, J. Zhu, Q. He, X. Yan, S. Wei, Z. Guo, Strain Sensitive Polyurethane Nanocomposites Reinforced with Multiwalled Carbon Nanotubes, Energy and Environment Focus, 3 (2014) 85-93.

[2] J. Zhu, M. Chen, H. Wei, N. Yerra, N. Haldolaarachchige, Z. Luo, D.P. Young, T.C. Ho, S. Wei, Z. Guo, Magnetocapacitance in magnetic microtubular carbon nanocomposites under external magnetic field, Nano Energy, 6 (2014) 180-192.

[3] S. Wei, Q. Wang, J. Zhu, L. Sun, H. Lin, Z. Guo, Multifunctional composite core-shell nanoparticles, Nanoscale, 3 (2011) 4474-4502.

[4] Y. Li, J. Zhu, S. Wei, J. Ryu, Q. Wang, L. Sun, Z. Guo, Poly (propylene) nanocomposites containing various carbon nanostructures, Macromolecular Chemistry and Physics, 212 (2011) 2429-2438.

[5] Y. Li, J. Zhu, S. Wei, J. Ryu, L. Sun, Z. Guo, Poly (propylene)/graphene nanoplatelet nanocomposites: melt rheological behavior and thermal, electrical, and electronic properties, Macromolecular Chemistry and Physics, 212 (2011) 1951-1959.

[6] H. Gu, J. Guo, X. Yan, H. Wei, X. Zhang, J. Liu, Y. Huang, S. Wei, Z. Guo, Electrical Transport and Magnetoresistance in Advanced Polyaniline Nanostructures and Nanocomposites, Polymer, (2014).

[7] X. Zhang, L.S. Loo, Study of Glass Transition and Reinforcement Mechanism in Polymer/Layered Silicate Nanocomposites, Macromolecules, 42 (2009) 5196-5207.

[8] M.C. Urbina, S. Zinoveva, T. Miller, C.M. Sabliov, W.T. Monroe, C.S.S.R. Kumar, 
Investigation of Magnetic Nanoparticle-Polymer Composites for Multiple-controlled Drug Delivery, The Journal of Physical Chemistry C, 112 (2008) 11102-11108.

[9] S. Narayanan, J. Choi, L. Porter, M.R. Bockstaller, Flexible Transparent Metal/Polymer Composite Materials Based on Optical Resonant Laminate Structures, ACS Applied Materials \& Interfaces, 5 (2013) 4093-4099.

[10] H. Wei, D. Ding, X. Yan, J. Guo, L. Shao, H. Chen, L. Sun, H.A. Colorado, S. Wei, Z. Guo, Tungsten Trioxide/Zinc Tungstate Bilayers: Electrochromic Behaviors, Energy Storage and Electron Transfer, Electrochimica Acta, 132 (2014) 58-66.

[11] H. Wei, X. Yan, Y. Li, S. Wu, A. Wang, S. Wei, Z. Guo, Hybrid electrochromic fluorescent poly (DNTD)/CdSe@ ZnS composite films, The Journal of Physical Chemistry C, 116 (2012) $4500-4510$.

[12] R. Gulotty, M. Castellino, P. Jagdale, A. Tagliaferro, A.A. Balandin, Effects of Functionalization on Thermal Properties of Single-Wall and Multi-Wall Carbon Nanotube-Polymer Nanocomposites, ACS Nano, 7 (2013) 5114-5121.

[13] H. Wei, D. Ding, S. Wei, Z. Guo, Anticorrosive conductive polyurethane multiwalled carbon nanotube nanocomposites, Journal of Materials Chemistry A, 1 (2013) 10805-10813.

[14] R.G. Mathews, R.D. Schwartz, M. Novotny, A. Zlatkis, Preparation and evaluation of isocyanate-based polyimides as liquid phase for gas chromatography, Analytical Chemistry, 43 (1971) 1161-1165.

[15] J.H. Lai, R.B. Douglas, K. Donohoe, Characterization and processing of polyimide thin 
films for microelectronics application, Industrial \& Engineering Chemistry Product Research and Development, 25 (1986) 38-40.

[16] W.Y. Chou, C.W. Kuo, H.L. Cheng, Y.S. Mai, S.T. Lin, C.C. Liao, C.C. Chang, F.C. Tang, J.S. Hwang, Novel Method of Pentacene Alignment Using Photoaligned Polyimide and Its Application in Thin-Film Transistors, Chemistry of Materials, 17 (2005) 3802-3802.

[17] S.R. Halper, R.M. Villahermosa, Cobalt-Containing Polyimides for Moisture Sensing and Absorption, ACS Applied Materials \& Interfaces, 1 (2009) 1041-1044.

[18] Y. Shoji, T. Higashihara, M. Tokita, J. Morikawa, J. Watanabe, M. Ueda, Thermal Diffusivity of Hexagonal Boron Nitride Composites Based on Cross-Linked Liquid Crystalline Polyimides, ACS Applied Materials \& Interfaces, 5 (2013) 3417-3423.

[19] Y. Xu, C. Chen, P. Zhang, B. Sun, J. Li, Pervaporation Properties of Polyimide Membranes for Separation of Ethanol + Water Mixtures, Journal of Chemical \& Engineering Data, 51 (2006) $1841-1845$

[20] D. Hill, Y. Lin, L. Qu, A. Kitaygorodskiy, J.W. Connell, L.F. Allard, Y.-P. Sun, Functionalization of Carbon Nanotubes with Derivatized Polyimide, Macromolecules, 38 (2005) $7670-7675$.

[21] I.S. Chung, C.E. Park, M. Ree, S.Y. Kim, Soluble Polyimides Containing Benzimidazole Rings for Interlevel Dielectrics, Chemistry of Materials, 13 (2001) 2801-2806.

[22] K. Akamatsu, M. Fujii, T. Tsuruoka, S.-i. Nakano, T. Murashima, H. Nawafune, Mechanistic Study on Microstructural Tuning of Metal Nanoparticle/Polymer Composite Thin Layers: 
Hydrogenation and Decomposition of Polyimide Matrices Catalyzed by Embedded Nickel Nanoparticles, The Journal of Physical Chemistry C, 116 (2012) 17947-17954.

[23] C.-M. Leu, Y.-T. Chang, K.-H. Wei, Polyimide-Side-Chain Tethered Polyhedral Oligomeric Silsesquioxane Nanocomposites for Low-Dielectric Film Applications, Chemistry of Materials, 15 (2003) 3721-3727.

[24] C.-C. Chang, W.-C. Chen, Synthesis and Optical Properties of Polyimide-Silica Hybrid Thin Films, Chemistry of Materials, 14 (2002) 4242-4248.

[25] K. Akamatsu, S. Ikeda, H. Nawafune, S. Deki, Surface Modification-Based Synthesis and Microstructural Tuning of Nanocomposite Layers: Monodispersed Copper Nanoparticles in Polyimide Resins, Chemistry of Materials, 15 (2003) 2488-2491.

[26] J.-g. Liu, Y. Nakamura, T. Ogura, Y. Shibasaki, S. Ando, M. Ueda, Optically Transparent Sulfur-Containing Polyimide-TiO2 Nanocomposite Films with High Refractive Index and Negative Pattern Formation from Poly(amic acid)-TiO2 Nanocomposite Film, Chemistry of Materials, 20 (2007) 273-281.

[27] P. Berger, N.B. Adelman, K.J. Beckman, D.J. Campbell, A.B. Ellis, G.C. Lisensky, Preparation and Properties of an Aqueous Ferrofluid, Journal of Chemical Education, 76 (1999) 943.

[28] M. Klokkenburg, C. Vonk, E.M. Claesson, J.D. Meeldijk, B.H. Erné, A.P. Philipse, Direct Imaging of Zero-Field Dipolar Structures in Colloidal Dispersions of Synthetic Magnetite, Journal of the American Chemical Society, 126 (2004) 16706-16707. 
[29] J. Guo, H. Gu, H. Wei, Q. Zhang, N. Haldolaarachchige, Y. Li, D.P. Young, S. Wei, Z. Guo, Magnetite-Polypyrrole Metacomposites: Dielectric Properties and Magnetoresistance Behavior, The Journal of Physical Chemistry C, 117 (2013) 10191-10202.

[30] Y. Zhu, Y. Fang, S. Kaskel, Folate-Conjugated Fe3O4@SiO2 Hollow Mesoporous Spheres for Targeted Anticancer Drug Delivery, The Journal of Physical Chemistry C, 114 (2010) $16382-16388$.

[31] X. Li, X. Huang, D. Liu, X. Wang, S. Song, L. Zhou, H. Zhang, Synthesis of 3D Hierarchical Fe3O4/Graphene Composites with High Lithium Storage Capacity and for Controlled Drug Delivery, The Journal of Physical Chemistry C, 115 (2011) 21567-21573.

[32] J. Bao, W. Chen, T. Liu, Y. Zhu, P. Jin, L. Wang, J. Liu, Y. Wei, Y. Li, Bifunctional Au-Fe3O4 Nanoparticles for Protein Separation, ACS Nano, 1 (2007) 293-298.

[33] H. Yu, M. Chen, P.M. Rice, S.X. Wang, R.L. White, S. Sun, Dumbbell-like Bifunctional $\mathrm{Au}-\mathrm{Fe} 3 \mathrm{O} 4$ Nanoparticles, Nano Letters, 5 (2005) 379-382.

[34] J.-f. Liu, Z.-s. Zhao, G.-b. Jiang, Coating Fe3O4 Magnetic Nanoparticles with Humic Acid for High Efficient Removal of Heavy Metals in Water, Environmental Science \& Technology, 42 (2008) 6949-6954.

[35] X. Zhang, J. Wang, R. Li, Q. Dai, R. Gao, Q. Liu, M. Zhang, Preparation of Fe3O4@C@Layered Double Hydroxide Composite for Magnetic Separation of Uranium, Industrial \& Engineering Chemistry Research, 52 (2013) 10152-10159.

[36] J.-H. Park, A.M. Derfus, E. Segal, K.S. Vecchio, S.N. Bhatia, M.J. Sailor, Local Heating of 
Discrete Droplets Using Magnetic Porous Silicon-Based Photonic Crystals, Journal of the American Chemical Society, 128 (2006) 7938-7946.

[37] H. Zeng, J. Li, Z.L. Wang, J.P. Liu, S. Sun, Bimagnetic Core/Shell FePt/Fe3O4 Nanoparticles, Nano Letters, 4 (2003) 187-190.

[38] WangWang, J. Luo, Q. Fan, M. Suzuki, I.S. Suzuki, M.H. Engelhard, Y. Lin, N. Kim, J.Q. Wang, C.-J. Zhong, Monodispersed Core-Shell Fe3O4@Au Nanoparticles, The Journal of Physical Chemistry B, 109 (2005) 21593-21601.

[39] Z. Xu, Y. Hou, S. Sun, Magnetic Core/Shell Fe3O4/Au and Fe3O4/Au/Ag Nanoparticles with Tunable Plasmonic Properties, Journal of the American Chemical Society, 129 (2007) 8698-8699.

[40] X. Sun, N. Frey Huls, A. Sigdel, S. Sun, Tuning Exchange Bias in Core/Shell FeO/Fe3O4 Nanoparticles, Nano Letters, 12 (2011) 246-251.

[41] X.Y. Chen, O.G. Nik, D. Rodrigue, S. Kaliaguine, Mixed matrix membranes of aminosilanes grafted FAU/EMT zeolite and cross-linked polyimide for $\mathrm{CO} 2 / \mathrm{CH} 4$ separation, Polymer, 53 (2012) 3269-3280.

[42] J. Guo, H. Gu, H. Wei, Q. Zhang, N. Haldolaarachchige, Y. Li, D.P. Young, S. Wei, Z. Guo, Magnetite-polypyrrole metacomposites: Dielectric properties and magnetoresistance behavior, Journal of Physical Chemistry C, 117 (2013) 10191-10202.

[43] J. Zhu, S. Wei, X. Chen, A.B. Karki, D. Rutman, D.P. Young, Z. Guo, Electrospun Polyimide Nanocomposite Fibers Reinforced with Core-Shell Fe-FeO Nanoparticles, The 
Journal of Physical Chemistry C, 114 (2010) 8844-8850.

[44] M.J.C. Ordoñez, K.J. Balkus Jr, J.P. Ferraris, I.H. Musselman, Molecular sieving realized with ZIF-8/Matrimid ${ }^{\circ}$ mixed-matrix membranes, Journal of Membrane Science, 361 (2010) 28-37.

[45] W. Yuan, H. Chen, R. Chang, L. Li, Synthesis and characterization of high performance $\mathrm{NaA}$ zeolite-polyimide composite membranes on a ceramic hollow fiber by dip-coating deposition, Desalination, 273 (2011) 343-351.

[46] D. Zhang, A.B. Karki, D. Rutman, D.P. Young, A. Wang, D. Cocke, T.H. Ho, Z. Guo, Electrospun polyacrylonitrile nanocomposite fibers reinforced with $\mathrm{Fe} 3 \mathrm{O} 4$ nanoparticles: Fabrication and property analysis, Polymer, 50 (2009) 4189-4198.

[47] Z.P. Smith, D.F. Sanders, C.P. Ribeiro, R. Guo, B.D. Freeman, D.R. Paul, J.E. McGrath, S. Swinnea, Gas sorption and characterization of thermally rearranged polyimides based on 3,3'-dihydroxy-4,4'-diamino-biphenyl (HAB) and 2,2'-bis-(3,4-dicarboxyphenyl) hexafluoropropane dianhydride (6FDA), Journal of Membrane Science, 415-416 (2012) $558-567$.

[48] Y.-Y. Yu, W.-C. Chien, T.-H. Wu, H.-H. Yu, Highly transparent polyimide/nanocrystalline-titania hybrid optical materials for antireflective applications, Thin Solid Films, 520 (2011) 1495-1502.

[49] H.J. Krenner, P.M. Petroff, Quantum posts with tailored structural, electronic and optical properties for optoelectronic and quantum electronic device applications, Solid State 
Communications, 149 (2009) 1386-1394.

[50] V.Z. Rizzo, R.D. Mansano, Electro-optically sensitive diamond-like carbon thin films deposited by reactive magnetron sputtering for electronic device applications, Progress in Organic Coatings, 70 (2011) 365-368.

[51] N.R. Khalid, E. Ahmed, Z. Hong, Y. Zhang, M. Ahmad, Nitrogen doped TiO 2 nanoparticles decorated on graphene sheets for photocatalysis applications, Current Applied Physics, 12 (2012) $1485-1492$.

[52] L. Ren, S. Wang, Tailoring optical and electrical properties of carbon nanotube networks for photovoltaic applications, Carbon, 48 (2010) 4397-4402.

[53] H. Wei, H. Gu, J. Guo, S. Wei, Z. Guo, Multiwalled carbon nanotubes with tuned surface functionalities for electrochemical energy storage, ECS Journal of Solid State Science and Technology, 2 (2013) M3008-M3014.

[54] H. Gu, J. Guo, H. Wei, Y. Huang, C. Zhao, Y. Li, Q. Wu, N. Haldolaarachchige, D.P. Young, S. Wei, Z. Guo, Giant magnetoresistance in non-magnetic phosphoric acid doped polyaniline silicon nanocomposites with higher magnetic field sensing sensitivity, Physical Chemistry Chemical Physics, 15 (2013) 10866-10875.

[55] R. Mishra, S.P. Tripathy, D. Sinha, K.K. Dwivedi, S. Ghosh, D.T. Khathing, M. Müller, D. Fink, W.H. Chung, Optical and electrical properties of some electron and proton irradiated polymers, Nuclear Instruments and Methods in Physics Research Section B: Beam Interactions with Materials and Atoms, 168 (2000) 59-64. 
[56] Y.-H. Yu, J.-M. Yeh, S.-J. Liou, Y.-P. Chang, Organo-soluble polyimide (TBAPP-OPDA)/clay nanocomposite materials with advanced anticorrosive properties prepared from solution dispersion technique, Acta Materialia, 52 (2004) 475-486.

[57] H. Kudo, S. Sudo, T. Oka, Y. Hama, A. Oshima, M. Washio, T. Murakami, Ion-beam irradiation effects on polyimide-UV-vis and infrared spectroscopic study, Radiation Physics and Chemistry, 78 (2009) 1067-1070.

[58] A.F. Ismail, R.A. Rahim, W.A.W.A. Rahman, Characterization of polyethersulfone/Matrimid® 5218 miscible blend mixed matrix membranes for O2/N2 gas separation, Separation and Purification Technology, 63 (2008) 200-206.

[59] Z.-M. Liang, J. Yin, H.-J. Xu, Polyimide/montmorillonite nanocomposites based on thermally stable, rigid-rod aromatic amine modifiers, Polymer, 44 (2003) 1391-1399.

[60] P. Uthirakumar, M.-K. Song, C. Nah, Y.-S. Lee, Preparation and characterization of exfoliated polystyrene/clay nanocomposites using a cationic radical initiator-MMT hybrid, European Polymer Journal, 41 (2005) 211-217.

[61] X. Zhang, Q. He, H. Gu, S. Wei, Z. Guo, Polyaniline stabilized barium titanate nanoparticles reinforced epoxy nanocomposites with high dielectric permittivity and reduced flammability, Journal of Materials Chemistry C, 1 (2013) 2886-2899.

[62] S.H. Kim, S.W. Na, N.E. Lee, Y.W. Nam, Y.-H. Kim, Effect of surface roughness on the adhesion properties of $\mathrm{Cu} / \mathrm{Cr}$ films on polyimide substrate treated by inductively coupled oxygen plasma, Surface and Coatings Technology, 200 (2005) 2072-2079. 
[63] S.H. Kim, S.H. Cho, N.E. Lee, H.M. Kim, Y.W. Nam, Y.-H. Kim, Adhesion properties of $\mathrm{Cu} / \mathrm{Cr}$ films on polyimide substrate treated by dielectric barrier discharge plasma, Surface and Coatings Technology, 193 (2005) 101-106.

[64] Q. Yang, H.H. Himstedt, M. Ulbricht, X. Qian, S. Ranil Wickramasinghe, Designing magnetic field responsive nanofiltration membranes, Journal of Membrane Science, 430 (2013) 70-78.

[65] J. Zhu, H. Gu, Z. Luo, N. Haldolaarachige, D.P. Young, S. Wei, Z. Guo, Carbon Nanostructure-Derived Polyaniline Metacomposites: Electrical, Dielectric, and Giant Magnetoresistive Properties, Langmuir, 28 (2012) 10246-10255.

[66] X. Zhang, O. Alloul, Q. He, J. Zhu, M.J. Verde, Y. Li, S. Wei, Z. Guo, Strengthened magnetic epoxy nanocomposites with protruding nanoparticles on the graphene nanosheets, Polymer, 54 (2013) 3594-3604.

[67] X. Zhang, O. Alloul, J. Zhu, Q. He, Z. Luo, H.A. Colorado, N. Haldolaarachchige, D.P. Young, T.D. Shen, S. Wei, Z. Guo, Iron-core carbon-shell nanoparticles reinforced electrically conductive magnetic epoxy resin nanocomposites with reduced flammability, RSC Advances, 3 (2013) 9453-9464.

[68] X. Yan, Q. He, X. Zhang, H. Gu, H. Chen, Q. Wang, L. Sun, S. Wei, Z. Guo, Magnetic Polystyrene Nanocomposites Reinforced with Magnetite Nanoparticles, Macromolecular Materials and Engineering, 299 (2014) 485-494.

[69] X. Qiao, T.-S. Chung, R. Rajagopalan, Zeolite filled P84 co-polyimide membranes for 
dehydration of isopropanol through pervaporation process, Chemical Engineering Science, 61 (2006) 6816-6825. 